Illinois State University

ISU ReD: Research and eData

Theses and Dissertations

3-19-2014

\title{
A Comparison of Functional Manual Reaction to Passive Joint Mobilization on Dorsiflexion and Star Excursion Reach Distance
}

Timothy Frederic Boerger

Illinois State University, boergertf@gmail.com

Follow this and additional works at: https://ir.library.illinoisstate.edu/etd

Part of the Kinesiology Commons

\section{Recommended Citation}

Boerger, Timothy Frederic, "A Comparison of Functional Manual Reaction to Passive Joint Mobilization on Dorsiflexion and Star Excursion Reach Distance" (2014). Theses and Dissertations. 137.

https://ir.library.illinoisstate.edu/etd/137

This Thesis is brought to you for free and open access by ISU ReD: Research and eData. It has been accepted for inclusion in Theses and Dissertations by an authorized administrator of ISU ReD: Research and eData. For more information, please contact ISUReD@ilstu.edu. 
A COMPARISON OF FUNCTIONAL MANUAL REACTION TO PASSIVE JOINT MOBILIZATION ON

DORSIFLEXION AND STAR EXCURSION REACH DISTANCE

Timothy F. Boerger

52 Pages

May 2014

Context: Joint mobilizations (JM) and functional manual reaction (FMR) are techniques

commonly utilized in rehabilitation to promote restoration of ankle dorsiflexion (DF).

Additionally, it is possible that JM have an effect upon postural control. Purpose: The purpose of this study was to investigate the comparative immediate effects of JM and FMR on DF and Star Excursion Balance (SEBT) reach distance in healthy subjects. Design: Randomized controlled trial. Setting: A university laboratory. Patients or other participants: 43 college aged subjects, 20 male, 23 female. Main outcome variables: Our variables were straight knee DF, bent knee DF, anterior SEBT, posteromedial SEBT, and posterolateral SEBT. Results: No significant effects were found as a result of either treatment for straight knee DF $(p=0.155)$, bent knee $(p=$ 0.937), anterior SEBT $(p=0.311)$, posteromedial SEBT $(p=0.105)$, or posterolateral SEBT $(p=0.382)$. Conclusions: We concluded that a single session of JM and FMR are not sufficient to cause an immediate effect on DF or SEBT balance. Key words: Ankle, manual therapy, dynamic balance, range of motion, $\mathrm{Y}$-balance test 
A COMPARISON OF FUNCTIONAL MANUAL REACTION TO PASSIVE JOINT MOBILIZATION ON

DORSIFLEXION AND STAR EXCURSION REACH DISTANCE

TIMOTHY F. BOERGER

A Thesis Submitted in Partial

Fulfillment of the Requirements

for the Degree of

MASTER OF SCIENCE

School of Kinesiology and Recreation

ILLINOIS STATE UNIVERSITY

2014 
C 2014 Timothy F. Boerger 
A COMPARISON OF FUNCTIONAL MANUAL REACTION TO PASSIVE JOINT MOBILIZATION ON DORSIFLEXION AND STAR EXCURSION REACH DISTANCE

TIMOTHY F. BOERGER

COMMITTEE MEMBERS:

Justin M. Stanek, Chair

Jody B. Brucker

Steven T. McCaw 


\section{ACKNOWLEDGMENTS}

I would like to thank my committee, Drs. Justin Stanek, Jody Brucker, and Steven McCaw who helped guide me through this process and devoted personal time to helping me complete this project. Additionally, I would like to thank Tyler Beauregard who aided me with data collection. I would like to thank all of my participants who contributed their time and energy towards being in my study. Finally, I would like to thank God for this opportunity, my wife, Megan, for her constant encouragement and understanding, and my friends and family. 
CONTENTS

Page

ACKNOWLEDGMENTS

CONTENTS

TABLES iii

FIGURES

CHAPTER

I. A COMPARISON OF FUNCTIONAL MANUAL REACTION TO PASSIVE JOINT MOBILIZATION ON DORSIFLEXION AND STAR EXCURSION REACH DISTANCE

Introduction $\quad 1$

Methods 3

Participants 3

Procedures 4

Statistical Analysis $\quad 8$

Results 9

Discussion 11

$\begin{array}{ll}\text { Conclusion } & 17\end{array}$

$\begin{array}{ll}\text { II. REVIEW OF RELATED LITERATURE } & 18\end{array}$

$\begin{array}{ll}\text { Anatomy } & 18\end{array}$

Pathologies Associated with Decreased Dorsiflexion $\quad 25$

Pathologies Associated with Decreased Postural Control 28

Joint Mobilizations 33

Functional Mobilizations $\quad 39$

Methods of Improving Postural Control 42

REFERENCES

47 


\section{TABLES}

\section{Tables}

1. Descriptive Statistics for Dorsiflexion ROM

2. Descriptive Statistics Star Excursion Balance Test Performance 


\section{FIGURES}

$\begin{array}{lll}\text { Figures } & \text { Page }\end{array}$

1. Hierarchal Representation of Allocation 4

2. Set up of Instrumented SEBT Device 6

3. Hand Placement for FMR Stabilizing Ankle and Mobilizing Leg 7 
CHAPTER I

A COMPARISON OF FUNCTIONAL MANUAL REACTION TO PASSIVE JOINT MOBILIZATION ON DORSIFLEXION AND STAR EXCURSION REACH DISTANCE

\section{Introduction}

Previous research has indicated that limited ankle dorsiflexion (DF) range of motion (ROM) is a risk factor for anklesprains ${ }^{1,2}$ and fractures. ${ }^{2}$ Less than $29.25^{\circ}$ straight-knee DF was reported as a predictor of ankle sprain in a prospective study. ${ }^{1}$ Similarly, less than $12.8^{\circ}$ straight leg and $21.5^{\circ}$ bent leg non-weight bearing contralateral DF was observed in subjects who sustained an ankle injury. ${ }^{2}$ Furthermore, DF limitations have been reported to contribute to decreased performance of the Star Excursion Balance Test (SEBT). ${ }^{3,4}$ Specifically, limited DF was moderately associated with decreased performance of the anterior direction of the SEBT in chronically unstable $\mathrm{e}^{3,4}$ and in healthy subjects. ${ }^{5}$

The SEBT is a measure of dynamic balance which additionally has been used as an injury screening tool and is commonly divided into the following 3 components: Anterior (ANT), posteromedial (PM), and posterolateral $(\mathrm{PL}) .^{6-8}$ It is known that high school basketball players who had a composite reach distance less than $94 \%$ of leg length were at greater risk of lower extremity injury. ${ }^{6}$ Additionally, right side scores less than $84.3,109.0$, and 105.6 for ANT, PM, and PL respectively increased injury risk. ${ }^{6}$ Similarly, recreationally active college students who had higher PL component scores had decreased ankle sprain injury rates in an epidemiological investigation. ${ }^{8}$ Furthermore, performance less than $89.6 \%$ composite reach distance while using 
an instrumented version of the test was related to a 3.5 times greater injury risk in collegiate football athletes. ${ }^{7}$ Finally, it has recently been reported that high compliance to a neuromuscular training program results in corresponding improvements in SEBT performance and reduction in lower extremity injury incidence. ${ }^{9}$

One technique previously reported to increase ankle $\mathrm{DF}^{10-13}$ and SEBT performance ${ }^{11}$ is joint mobilization (JM). ${ }^{12,13}$ While it is likely that improvements in SEBT performance following $\mathrm{JM}$ are related to improvements in DF, it is also possible that improved performance is related to the stimulation of ankle proprioceptors. ${ }^{11,12}$ Since it has been suggested that proprioceptors are located at ligamentous insertions, ${ }^{14}$ it is probable that repetitive oscillations at the end range of joint play stimulate these receptors.

Since the research on JM and balance suggests that dynamic balance does not improve immediately, but does improve over time, ${ }^{11,12}$ and static balance improves immediately but not over 2 weeks; ${ }^{12,15}$ a dynamic mobilization may be necessary to improve SEBT acutely. Functional Manual Reaction (FMR) is a dynamic mobilization technique thought to improve DF and function, ${ }^{16}$ however, no research to date has investigated this concept. FMR, as described by Gary Gray, is a weight bearing technique combining several theories to improve function. ${ }^{16,17}$ Specifically, it combines the proprioceptive neuromuscular facilitation theory of treating patients in all three cardinal planes simultaneously with overpressure joint mobilizations. ${ }^{16,17}$ The FMR concept has been described as a technique which can be used during both rehabilitation and functional training, ${ }^{17}$ and may cause rapid improvements in DF and gait. ${ }^{16}$ Since FMR involves a mobilization combined with active movement, it is possible that FMR will 
stimulate a mechanical response as well as joint mechanoreceptors causing a rapid adaptation in dynamic balance not seen with traditional JM.

To date, no research has been conducted investigating the effects of JM or FMR on improving DF and SEBT in uninjured subjects who were at risk for ankle injury. For this reason, the purpose of this study was to compare a single treatment of JM or FMR on DF and SEBT reach distance in at risk healthy subjects. We hypothesized that FMR would result in a greater difference in both DF and SEBT than traditional joint mobilization or non-treatment controls.

\section{Methods}

This study employed a single session, assessor-blinded, randomized controlled laboratory trial on uninjured subjects. The DVs were SL DF, BL DF, ANT, PM, and PL. The IV was treatment group. All baseline and post-testing procedures were conducted by a single investigator who was blinded to group allocation, and all treatments were performed by a separate, single researcher who was blinded to baseline measures. For internal consistency, we compared the dominant ankle on each subject with each subject randomized between the three conditions. The dominant ankle was defined as the leg which one would use to kick a soccer ball. The 3 possible conditions were JM, FMR, or Control. Data were collected prior to and immediately following the administration of the treatment.

\section{Participants}

For this investigation, 62 subjects were recruited to participate in our study and of these, 43 met all inclusion and exclusion criteria and were considered at risk for injury. Subjects were considered at risk for ankle injury if they were assessed to have $<30^{\circ}$ weight bearing SL DF as previously described by Willems et al. ${ }^{1}$ Included subjects were 20 males (age: $21.71 \pm 1.49$ years, height: $178.28 \pm 5.83 \mathrm{~cm}$, weight: $85.93 \pm 13.40 \mathrm{~kg}$ ) and 23 females (age: $22.09 \pm 1.66$ 
years, height: $166.02 \pm 8.32 \mathrm{~cm}$, weight: $68.88 \pm 13.36 \mathrm{~kg}$ ). Subjects were recruited from the host university's School of Kinesiology and Recreation and the Student Fitness Center. Subjects were included if they participated in moderate physical activity a minimum of 3 times per week for 30 minutes. They were excluded if they 1) had an ankle sprain or fracture to either limb in the previous 6 months; 2 ) if they had an inner ear infection, central nervous system injury or illness, arthritic condition, or vestibular illness in the previous 6 months, or uncorrected vision impairment; 3) any previous ankle surgery or 4 ) less than $10^{\circ} \mathrm{DF}$ ROM ${ }^{18}$ because this cannot be considered uninjured, or greater than $30^{\circ} \mathrm{DF}$ ROM,${ }^{1}$ because this is not considered at risk. All subjects signed informed consent as approved by the host university's Institutional Review Board.

Figure 1. Hierarchal Representation of Allocation

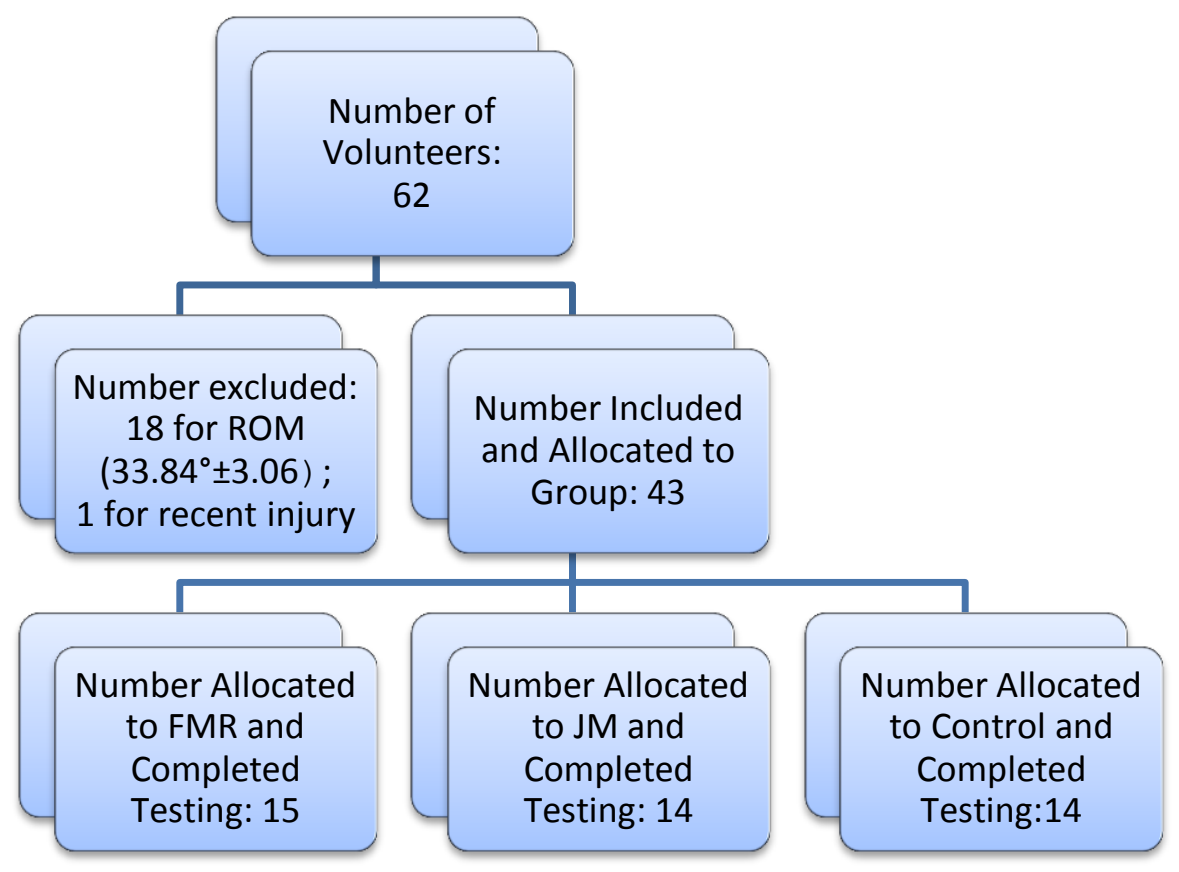

\section{Procedures}

Following recruitment, subjects were tested to assess DF ROM and SEBT. These measures were conducted by the same examiner for all subjects and were randomized to avoid 
testing bias. The same testing procedures were conducted following the treatment. Following recruitment and baseline testing, subjects were assigned to treatment and control conditions by random allocation, which was concealed from the researcher who determined inclusion eligibility and was generated a priori in Excel.

Dorsiflexion range of motion was assessed in a weight-bearing position by having the subject place the test foot posterior to their body so that the entire foot was flat on the floor. A digital inclinometer (PRO 3600, PennTool CO, Maplewood, NJ) was normalized to a vertical reference and placed along the shaft of the fibula similar to Denegar et al. ${ }^{19}$ This measure was taken a total of 3 times and averaged as previously performed by Denegar et al. ${ }^{19}$ For bent knee $\mathrm{DF}(\mathrm{BL})$, subjects were instructed to bend the knee of the test extremity $30^{\circ}$ and hold this position for the knee while lunging forward with the opposite leg similar to Basnett et al. ${ }^{3}$ Measurements were taken when the subject reached a position of maximal DF while maintaining the heel flat on the ground and $30^{\circ}$ of knee flexion. For straight knee DF (SL), subjects stood with the test leg straight with the heel touching the floor and lunged forwards with the contralateral leg until maximum DF was attained while keeping the test side knee straight and heel in contact with the floor. ${ }^{19}$ Assessor intra-tester reliability was considered good for both $\mathrm{BL}\left(\mathrm{ICC}=0.911, \mathrm{SEM}=1.67^{\circ}\right)$ and $\mathrm{SL}\left(\mathrm{ICC}=0.90, \mathrm{SEM}=1.46^{\circ}\right)$ For all measures of Standard Error of Measure (SEM), the formula was SEM $=S D^{*} \sqrt{ }(1-I C C)$.

SEBT testing was performed on an instrumented Y-Balance device (Move2Perform, Evansville, IN). This configuration represents the directions for anterior (ANT), posteromedial (PM), and posterolateral (PL) components of the SEBT. Subjects stood with their toes on the intersection point and simultaneously performed a squat and reach with the contralateral limb into each respective direction, pushing the testing block maximally along the rail, and returning 
to the starting position. The distance of reach was observed on the rail and rounded down to the nearest $0.5 \mathrm{~cm}$. Each subject was given 3 trials for each direction as well as 4 practice trials to familiarize themselves with the procedure. Subjects were given up to 1 minute rest between each trial. Order of testing for each component was randomized for each subject a priori. The maximum reach distance was extracted from the data for each component. Reach distance was expressed as a percentage of the leg length from the ASIS to the medial malleolus. For SEBT measures, our observed intra-tester reliability was ICC $=0.984$. Our SEM for SEBT was ANT $=1.68 \%, P M=2.19 \%, P L=2.18 \%$

\section{Figure 2. Set up of Instrumented SEBT Device}

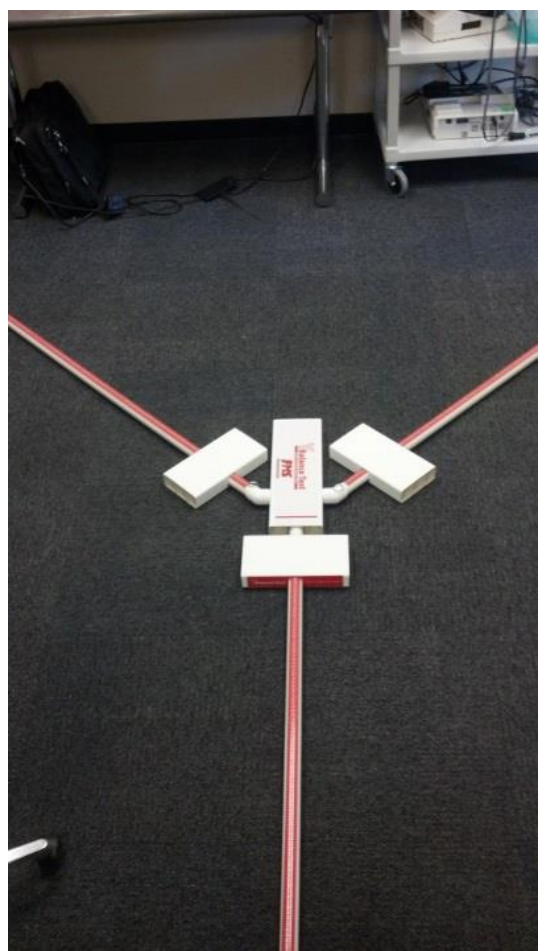

Immediately following the assessment of all pre-treatment measures subjects received their allocated treatment. JM treatment consisted of 2 sets of 2 minutes of mobilization with 1 minute rest between sets, as previously utilized. ${ }^{11,12}$ Each mobilization set consisted of Grade III oscillations which are defined as a large amplitude mobilization beginning in the mid capsular 
range extending to the end of the capsular range. ${ }^{20}$ Approximately 50 oscillations were performed during each set as conducted previously. ${ }^{12}$ An anterior to posterior glide was conducted with pressure from the webspace of the researcher's hand against the anterior talus with the talocrucal joint in neutral. The opposite hand of the clinician stabilized the tibia against the plinth.

\section{Figure 3. Hand Placement for FMR Stabilizing Ankle and Mobilizing Leg}

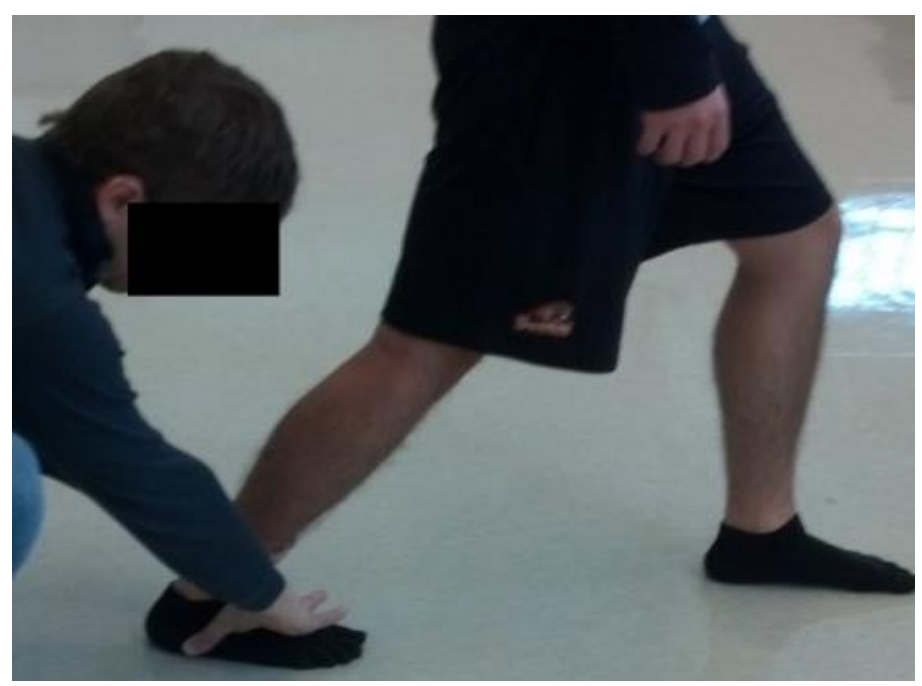

FMR treatment was performed on the ground in weight-bearing with the treatment leg positioned posterior to the contralateral leg in a lunge position. The researcher applied an anterior glide to the tibia through the palm of the hand placed immediately superior to the malleoli while additionally externally rotating the lower leg. Simultaneously, the subject alternated leaning toward and away from the clinician. The final component occurring during this treatment involved the subject holding onto a door frame with the contralateral arm for support and additional rotation. ${ }^{16}$ Three sets of 15 repetitions were applied to the subject with 1 minute rest between sets. 
For consistent treatment involving the FMR, a single researcher positioned all subjects so that the treatment leg was visually in $10^{\circ}$ hip extension, $15-20^{\circ}$ knee flexion, and $10^{\circ}$ ankle dorsiflexion prior to treatment. The non-treatment leg was positioned in approximately $30^{\circ}$ hip flexion, $20^{\circ}$ knee flexion, and $5^{\circ}$ plantar flexion. Subjects then performed a mini-lunge to a position where the knee of the non-treatment leg was superior to and in line with the great toe, until they felt a hard restriction to movement at their ankle. See Figure 3.

All treatments were administered by the same Certified Athletic Trainer with experience with joint mobilization procedures and completion of the FMR home-study course and clinical experience in FMR. All treatments were administered immediately after baseline testing and were immediately followed by post-testing. In order to maintain external validity, we performed each treatment as it is recommended rather than controlling for treatment duration.

\section{Statistical Analysis}

Multiple three way ANCOVAs were performed to assess for group effects for each dependent variable. Dependent variables were ANT, PM, and PL reach as well as BL, and SL dorsiflexion ROM. The independent variable was group allocation with 3 levels. The covariate variable was the pretest measure for each dependent measure. For this investigation, all statistical tests were conducted as 2-tailed since only a moderate correlation exists between DF and SEBT. Effect sizes were calculated by using Cohen's $d$ for each dependent variable. The formula for calculating the time order effect size was Post-test - Pre-test divided by Pre-Test standard deviation and the formula for calculating group effect sizes was Treatment Treatment divided by the larger standard deviation. Independent samples T-tests were performed to determine significant differences at baseline. All calculations were conducted in 
SPSS version 20.0 (SPSS, INC Chicago, IL). Significance was set a priori at $p<0.05$. Effect sizes were categorized as trivial $(\leq 0.20)$, small $(0.21-0.49)$, moderate $(0.50-0.79)$, and large $(\geq 0.80) .{ }^{21}$

\section{Results}

Upon arrival for testing, 19 subjects were excluded from participation due to not meeting inclusion and exclusion criteria. Eighteen subjects were excluded due to having SL DF values greater than $30^{\circ}$ and 1 subject was excluded due to having sustained an ankle sprain approximately 2 months prior to testing. Multiple independent samples t-test revealed no significant differences between groups at baseline for any measure $(p>0.05)$.A description of the recruitment, allocation, and testing can be found in Figure 3 . Unadjusted means $\pm S D$, mean differences, and Pre - Post Effect sizes, and adjusted group effect sizes for DF and SEBT are reported in Table 1 and Table 2 respectively.

Table 1. Descriptive Statistics for Dorsiflexion ROM

\begin{tabular}{|c|c|c|c|c|c|c|c|c|}
\hline & \multirow[b]{2}{*}{ Group } & \multirow[b]{2}{*}{ Pre-Test } & \multirow[b]{2}{*}{ Post-Test } & \multirow[b]{2}{*}{ Difference } & \multicolumn{4}{|c|}{ Cohen's d } \\
\hline & & & & & Pre - Post & FMR & JM & Control \\
\hline \multirow[t]{4}{*}{$S L^{\circ}$} & FMR & $22.83(3.60)$ & $23.68(4.58)$ & 0.84 & 0.23 & 1 & 0.44 & 0.14 \\
\hline & $\mathrm{JM}$ & $25.10(3.32)$ & $23.60(4.24)$ & -1.50 & -0.45 & & 1 & -0.32 \\
\hline & Control & 24.31(3.34 & $24.30(2.73)$ & -0.01 & 0.00 & & & 1 \\
\hline & Total & $24.05(3.48)$ & 23.86(3.87) & -0.20 & -0.01 & & & \\
\hline \multirow[t]{4}{*}{$\mathrm{BL}^{\circ}$} & FMR & $29.08(6.78)$ & $30.50(5.37)$ & 1.41 & 0.21 & 1 & -0.03 & 0.05 \\
\hline & $\mathrm{JM}$ & $29.45(5.32)$ & $30.97(6.36)$ & 1.53 & 0.29 & & 1 & 0.07 \\
\hline & Control & $32.47(4.96)$ & $33.00(5.33)$ & 0.53 & 0.11 & & & 1 \\
\hline & Total & $30.30(5.83)$ & $31.47(5.67)$ & 1.16 & 0.20 & & & \\
\hline
\end{tabular}


Table 2. Descriptive Statistics Star Excursion Balance Test Performance

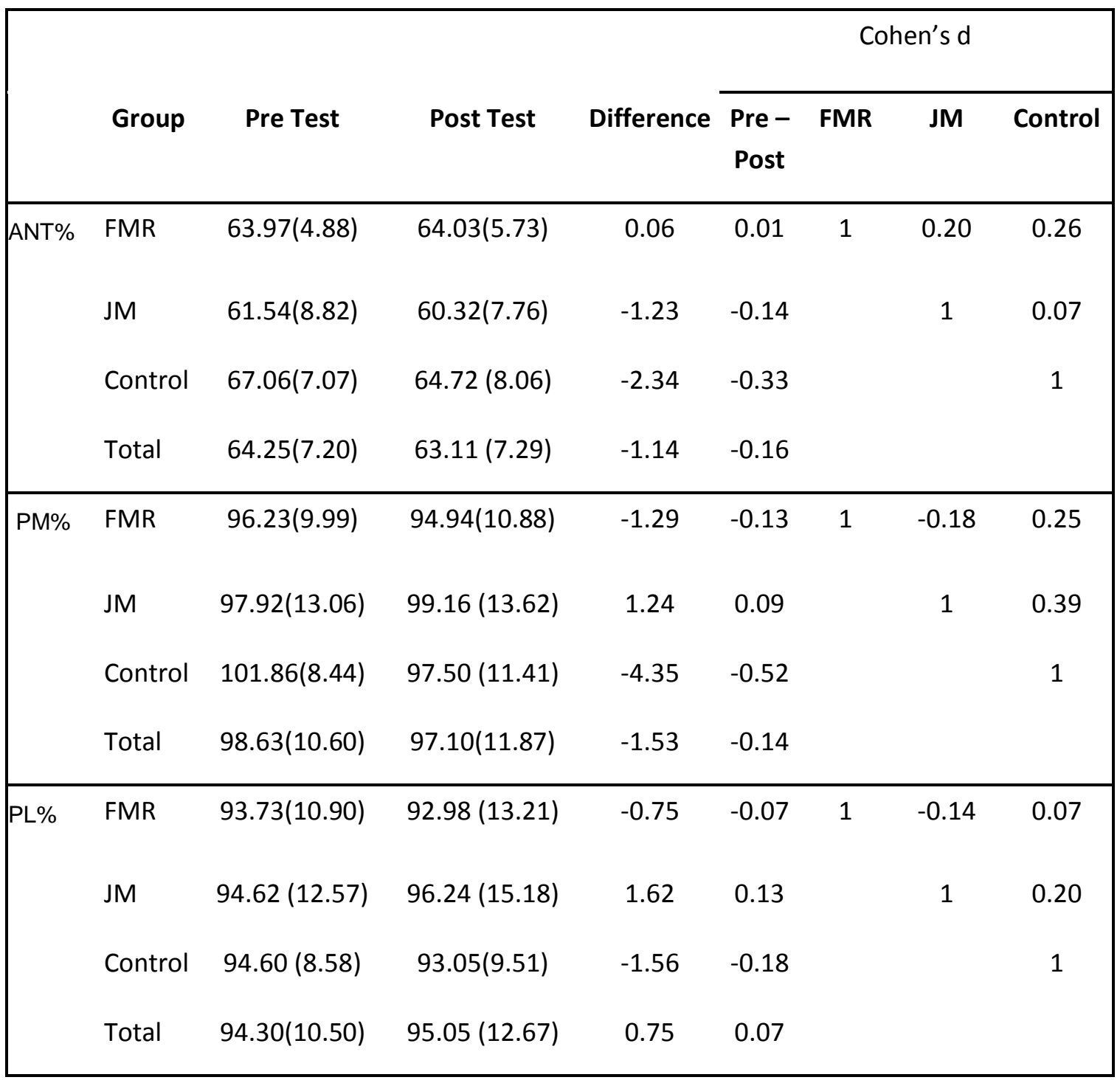

Multiple separate ANCOVAs were used to evaluate for SL and BL post-test group effects adjusted based on for pre-test measures. For SL DF no significant group differences were observed $\left(F_{2,42}=1.959, p=0.155\right)$ between groups at the post-test time point. The adjusted post-test means \pm SD for FMR was $24.72 \pm 4.58$, JM was $22.71 \pm 4.24$, and control was $24.08 \pm$ 2.73. For $B L D F$ no significant group differences were observed $\left(F_{2,42}=0.066, p=0.937\right)$. The adjusted post-test means \pm SD for FMR was $31.50 \pm 5.37$, JM was $31.68 \pm 6.36$, and Control was $31.23 \pm 5.33$ 
Multiple separate ANCOVAs was used to evaluate for ANT, PL, and PM post-test group effects controlling for pre-test measures. For ANT no significant group differences were observed $\left(F_{2,42}=1.204, p=0.311\right)$. The adjusted post-test means \pm SD for FMR was $64.29 \pm 5.73$, JM was $62.75 \pm 7.76$, and control was $62.21 \pm 8.06$. For PM no significant group differences were observed $\left(F_{2,42}=2.394, p=0.105\right)$. The adjusted post-test means \pm SD for FMR was $97.43 \pm$ 10.88 , JM was $99.87 \pm 13.62$, and control was $94.53 \pm 11.41$. For PL no significant group differences were observed $\left(F_{2,42}=0.988, p=0.382\right)$. The adjusted post-test means \pm SD for FMR was $93.80 \pm 13.21$, JM was $95.94 \pm 15.18$, and control was $92.92 \pm 9.51$.

\section{Discussion}

In an attempt to compare the effects of FMR to JM on DF and SEBT reach in a sample of at risk, uninjured subjects, no significant differences were observed. While effect size values ranged from trivial to moderate for time effects and trivial to small for group effects, values for BL for the JM group increased as well as ANT and PM for the control decreased greater than our SEM. Since we limited our sample to those subjects who had reduced DF, it is logical that we found smaller values $\left(\mathrm{SL}=24.05^{\circ}, \mathrm{BL}=30.30^{\circ}\right)$ than previously reported by Willems et al. ${ }^{1}(\mathrm{SL}$ injured $=25.88^{\circ}$, uninjured $29.25^{\circ}$, BL injured $=32.88^{\circ}$, uninjured $\left.34.85^{\circ}\right)$. Our SEBT values (ANT $=64.25 \%, \mathrm{PM}=98.63 \%, \mathrm{PL}=94.30 \%$ ) were slightly different from what has been previously established for recreationally active college students (ANT $=83.5 \%, \mathrm{PM}=85.5 \%, \mathrm{PL}=89.8 \%),{ }^{8}$ however, an average of our three components, (85.73\%) was similar to theirs (86.27\%). Likewise, our average is somewhat smaller than previously reported as at risk while using a $Y$ balance instrument $(89.6 \%)^{7}$ suggesting that our sample was also at risk for injury based upon SEBT scores. One issue in designing our investigation that we observed was that DF has

previously been measured as an average of 3 measures, ${ }^{19}$ whereas, instrumented SEBT has been 
measured as the maximum value. ${ }^{7}$ This represents an inconsistency of measurement, however, it is how the previous research has been conducted.

One obvious reason for our lack of significant effect could have been our choice to use a sample of at-risk uninjured subjects with limited DF. It is possible that in this population the limiting factor to DF is soft tissue in nature rather than arthrokinematic. This would be consistent with results of Willems et al. ${ }^{1}$ who observed that Straight Leg DF was related to injury risk but not Bent Leg DF. If this is in fact true, it is possible that SL DF, limited by musculotendinous structures, causes injury which in turn cause changes in arthrokinematic motion. However, since FMR is advocated for functional training both Pre and Post injury, regardless of whether an exact cause for DF restriction is known, ${ }^{17}$ it is surprising that we did not see a difference as a result of this treatment. Since we did not observe an immediate change in our investigation on at risk subjects, we recommend repeating this investigation in a post-injury sample.

Another possible explanation for the lack of effect of treatment on DF is the immediate effects nature of our study. It is possible that a single treatment is not sufficient to cause rapid changes in either DF or SEBT. Similarly, Cosby et al. ${ }^{22}$ did not observe an immediate effect of JM in a sample of acutely injured subjects. Unlike Cosby et al., ${ }^{22}$ we chose to perform ROM in weight bearing with the knee both straight and bent, which we felt gave us a more accurate assessment of any immediate DF changes through using gravity to cause a greater tissue stretch. Conversely, Landrum et al. ${ }^{13}$ and Hoch and McKeon ${ }^{12}$ both found that DF was immediately increased as a result of JM treatments. Landrum et al., ${ }^{13}$ however, performed only an assessment of SL non-weight bearing DF, and Hoch and McKeon ${ }^{12}$ assessed only weight bearing BL DF. Since previous research ${ }^{19}$ has demonstrated larger values in weight bearing than non- 
weight bearing, we believe a subjects ground reaction force is able to cause a greater excursion of joint motion.

In regard to SL DF, our results revealed a non-significant, small, negative difference $1.5^{\circ}$ which was less than our SEM $\left(1.67^{\circ}\right)$ for JM. By contrast, the previous research on the immediate effects of JM on SL DF has thus far been inconclusive. More specifically, Landrum et al. ${ }^{13}$ observed a significant difference following mobilization, whereas, Cosby et al. ${ }^{22}$ did not. In addition to the previously mentioned short term investigations, a longer prospective trial indicated that JM improved SL DF more rapidly, and greater than a control treatment. ${ }^{10}$ It is possible that if we and Cosby et al. ${ }^{22}$ had conducted a longer duration investigation we may have found significance.

With respect to BL DF, we found only a non-significant, small time effect for JM and trivial group effect. However, our pre-post difference $\left(1.53^{\circ}\right)$ was greater than our SEM $\left(1.46^{\circ}\right)$ suggesting that the difference was not related to measurement error. While Hoch and McKeon ${ }^{12}$ did not report effect sizes, calculating theirs as we did revealed a somewhat larger group effect $(d=0.14)$ in their study than ours $(d=0.07)$. Unfortunately, as they ${ }^{12}$ did not also report both pre and post-test measures, we cannot compare our time effect size to theirs. This difference in effect size as well as differences of statistical tests used to evaluate the data likely resulted in the different outcome. A longer prospective investigation of JM has reported significance ${ }^{11}$ and if we had conducted a longer duration treatment, it is possible ours would have also observed significance.

Unlike previous research on active, functional mobilizations, ${ }^{23-25}$ we did not observe an acute difference in DF ROM. First, this may be due to differences in technique. We chose to perform an FMR rather than the Mulligan technique. While the mechanical premise is similar, 
(i.e. apply an anterior translation of the leg with respect to the talus during active DF), between Mulligan ${ }^{23-25}$ and $\mathrm{FMR}^{16,17}$ we did not see results consistent with research on Mulligan. One major reason why our results were not consistent with Mulligan research may be the difference of sample population. ${ }^{23-25}$ Specifically, all three of the previous investigations on Mulligan have used unhealthy samples. ${ }^{23-25}$ We chose to apply the FMR technique due to an absence of research, our clinical familiarity with the technique, and because this technique additionally incorporates a rotational component which is also required for proper DF. While a direct comparison is not possible due to a difference in measurement technique, ${ }^{23-25}$ effect sizes allow us an approximation. Vicenzino et al. ${ }^{24}$ reported a somewhat larger time effect than our study $(d=0.4)$, whereas, calculating effect sizes from the other two ${ }^{23,25}$ reveal a slightly smaller $(d=0.16)^{23}$ and slightly larger $(d=0.28)^{25}$ effect size measures $(d=0.16-0.28)$. Time effect sizes for the control condition $(d=-0.06-0.10){ }^{23-25}$ were similarly trivial to ours $(d=.10)$.

Regarding SEBT reach distance, we did not see any effect as a result of treatment. This may be due to a lack of sensitivity of the balance measure to any instantaneous neuromuscular or mechanical changes. While previous research ${ }^{3-5}$ has demonstrated a relationship between DF and SEBT performance, we did not observe a corresponding relationship in DF and SEBT change. This is consistent with previous research on immediate effects of JM on DF and SEBT which also did not see a relationship between improving DF and improving SEBT performance. ${ }^{12}$ In this previous investigation, DF significantly improved, whereas, SEBT performance, in particular ANT reach, did not. ${ }^{12}$ In a longer duration investigation, however, that the relationship between DF and SEBT was observed in a longer term investigation on $\mathrm{JM}^{11}$ Based on the findings of our study, it would be logical to conduct a longer duration investigation while assessing DF and dynamic balance. 
Additionally, while our SEBT results did not reach significance, ANT (-2.34\%) and PM (4.35\%) reach distance had a non-significant trend towards reduced dynamic balance in the Control group. In both of these cases the decrease in reach distance exceeded the SEM (ANT = $1.68, \mathrm{PM}=2.19)$. This negative trend was not observed in the treatment groups, whose results were within the SEM. It is not clear from our investigation, or previous research, why the control group would have a trend toward decreasing balance when the treatment groups did not decrease as well.

Dynamic balance is thought to be largely governed by the presence of proprioceptors in articular, ligamentous, and musculotendinous tissues. ${ }^{26}$ It is possible that slow oscillations such as the grade III mobilization in our study may stimulate the Ruffini endings which tend to be slow adapting rather than Pacinian corpuscles which are more rapidly adapting and dynamic. ${ }^{26}$ It is likewise possible that the FMR did not sufficiently stimulate the Pacinian corpuscles to cause a change in dynamic balance. Unfortunately, previous research has not yet come to a conclusion regarding the comparative presence of different fiber types in different ligamentous structures. ${ }^{14,27,28}$ Research ${ }^{14}$ has noted a high prevalence of Ruffini endings in multiple structures, however, other researchers ${ }^{27,28}$ have reported a greater amount of Pacinian Corpuscles throughout ankle ligaments. Since researchers ${ }^{14,27}$ seem to agree that Ruffini endings may be highly prevalent in the posterior tibiotalar ligament, it is possible that posterior joint mobilizations, stimulating this structure, could cause an increase in slow adaptive proprioception. If neurophysiological changes as a result of grade III JM are in fact stimulated by Ruffini endings, improvements could be expected in static balance immediately and dynamic balance following multiple treatments as a result of the stimulating the Pacinian Corpuscles. 
Likewise treatments with grade IV or V may result in more rapid changes in proprioception due to greater stimulation of fast adapting fibers.

Regarding clinical practice, we would suggest that our results indicate that in an uninjured sample, a single session of the FMR or JM will not result in an immediate reduction in injury risk. While anecdotal evidence for $\mathrm{FMR}^{16,17}$ and empirical evidence for $\mathrm{JM}^{10-13,15}$ suggest that improvements in DF and function are possible, we were not able to observe this. It is our recommendation that clinicians continue to use their experience and judgment to determine the usefulness of each of these treatments for their patients.

There were several strengths to this investigation. While other research studies used a cross-over design, we chose to employ a parallel group comparison investigation. This allowed us to use true comparison groups and a control group without any potential confounder related to a cross over design. Additionally, the assessor and treating researchers were both blinded and group allocation was concealed to the assessor, who made inclusion determination.

We realize that no research study is without limitations. First, the study was conducted on uninjured, at-risk subjects. This limits the generalizability of the study to unhealthy patients. We chose this patient population in order to assess the effectiveness of these treatments for injury prevention methods following pre-injury screening. Second, the study is limited by only assessing the immediate effects of the treatment on DF and SEBT. We conducted our investigation in this manner in order to determine what, if any, effect these treatments may have had on injury risk factors. Also, while groups were not significantly different at baseline, some of the group differences at baseline could be considered meaningful. We attempted to control for this limitation by performing multiple ANCOVAs with the baseline measure as the covariate. 
Future research should be conducted with a longer intervention period to observe any cumulative changes with these treatments as well as if a decrease in injury rates corresponds to these changes. For the purposes of our study, it was not practical to maintain this duration of follow up. Additionally, future research should be conducted to examine other balance measures, i.e. static and drop landing postural sway, and other neurophysiological changes i.e. Hoffmann Reflex. This research would continue to elucidate the outcomes of how mobilization techniques stimulate proprioceptors. Future studies should also compare the benefits of JM, FMR, and MWM on arthrokinematics and DF. This will help to increase the construct validity of using these treatments in a clinical setting. Finally, future investigations should examine if measuring DF as a maximum rather than mean value improves validity of the measure. We were not able to perform this assessment in our investigation due to this concept being outside of our research purpose.

\section{Conclusion}

In conclusion, this investigation found that a single session of JM and FMR were insufficient to cause changes in weight bearing DF and SEBT reach distance. These findings build upon the theoretical foundation for future research on JM in multiple populations as well as comparing passive to dynamic mobilization techniques. 


\section{CHAPTER II}

\section{REVIEW OF RELATED LITERATURE}

\section{Anatomy}

The true ankle, talocrural, articulation is formed by the junction of the distal tibia, fibula, and the talus bones. ${ }^{29}$ The ankle joint has been classified as a synovial joint. ${ }^{29}$ Together, the tibia and fibula form the proximal articulating surface, known commonly as the ankle mortise. ${ }^{29}$ Specifically, the tibia forms the medial and superior aspect of the mortise, whereas, the fibula forms the lateral articulation with the talus. ${ }^{29}$ The superior, rounded surface of the talus, therefore, forms the distal articulation of the talocrural joint. ${ }^{29}$ The talocrural joint is partly supported by the fibrous capsule which runs from the malleoli and joint surfaces to the talar bone. ${ }^{29}$ In addition, the synovial capsule closely aligns with the fibrous capsule, but can run proximally into the distal tibiofibular joint. ${ }^{29}$ The primary motion of the talocrural joint is in the sagital plane, referred to as plantarflexion(PF) and dorsiflexion (DF). ${ }^{29}$ Blood supply to the talocrural joint is provided by the posterior and anterior tibial arteries as well as the fibular artery through the malleolar branch. ${ }^{29}$

In addition to the talocrural joint, the distal tibia and fibula form an articulation. ${ }^{29}$ In contrast to the talocrural joint, the distal tibiofibular joint is a fibrous, syndesmotic joint. ${ }^{29} \mathrm{~A}$ triangle shaped surface on the medial aspect of the distal fibula forms an articulation with the lateral facet of the distal tibia. ${ }^{29}$ While no movement occurs between the articular surfaces of 
this joint, separation of the surfaces occurs during dorsiflexion as the wider talus forms a more closed-packed position with the mortise. ${ }^{29}$ The tibiofibular joint is innervated by branches of the saphenous, tibial, and fibular nerves. ${ }^{29}$ Vascularity is provided by perforating branches of the fibular artery as well as from the anterior and posterior arteries through the medial malleolar branches. $^{29}$

Of additional importance to the broader view of the ankle joint is the subtalar joint. ${ }^{29}$ Here, the superior surface of the calcaneus articulates with the underside of the talus. ${ }^{29}$ Specifically, the posterior articular facet of the calcaneus supports the posterior talus. ${ }^{29}$ The subtalar joint is partially supported by a synovial capsule and articular cartilage which surrounds the facets. ${ }^{29}$ This joint articulates in the frontal plane and is responsible for much of the inversion and eversion of the ankle. ${ }^{29}$ The arteries supplying the subtalar joint include the posterior fibular and tibial arteries. ${ }^{29}$ Innervation to the subtalar joint arises from the medial and lateral plantar nerves as well as the deep fibular nerve. ${ }^{29}$

Numerous ligaments stabilize the several joints that make up the ankle complex. ${ }^{29}$ Of particular importance to the talocrural joint are the medial and lateral collateral ligaments and their subdivisions. ${ }^{29}$ The lateral ligament is a complex of the anterior talofibular (ATF), calcaneofibular (CF), and the posterior talofibular (PTF) ligaments. ${ }^{29}$ The ATF arises from the anterior lateral malleolus travelling anteromedially and attaches to the neck of the talus. ${ }^{29}$ The ATF is a relatively weak ligament which is commonly injured. ${ }^{29}$ By comparison, the $\mathrm{CF}$ is a cylindrically shaped ligament also arising from the anterior lateral malleolus extending posteriorly and inferiorly to the lateral calcaneus. ${ }^{29}$ The PTF ligament is oriented on the posterior aspect of the talocrural joint and is a relatively large and resilient ligament. ${ }^{29}$ 
By contrast several, strong ligaments provide support to the medial talocrural joint. ${ }^{29}$ The medial collateral ligament complex, or deltoid ligament, consists of the tibiocalcaneal, talonavicular, anterior tibiotalar, and posterior tibiotalar ligaments. ${ }^{29}$ The tibiocalcaneal ligament extends from the apex of the medial malleolus inserting into the sustentaculum tali of the calcaneus. ${ }^{29}$ The posterior tibiotalar also arises from the apex of the medial malleolus inserting into the medial tubercle of the talus. ${ }^{29}$ The tibionavicular ligament extends from the anterior medial malleolus, inserting into the superior navicular bone. ${ }^{29}$ The anterior tibiotalar also originates from the anterior medial malleolus and extends to the anterior aspect of the talus. $^{29}$

The tibiofibular joint is supported superiorly by a interosseous ligament which joins the interosseous membrane of the lower leg. ${ }^{29}$ Additional support is provided by anterior and posterior inferior tibiofibular ligaments. ${ }^{29} \mathrm{~A}$ branch of the posterior inferior tibiofibular ligament, known as the inferior transverse ligament, forms the posterior wall of the articular surface of the ankle. ${ }^{29}$ By comparison, the subtalar joint is stabilized by medial, lateral, posterior, and interosseous ligaments, which are rarely involved in pathology. ${ }^{29}$

Numerous muscles cross and interact with the joints of the ankle, mostly arising from the compartments of the lower leg. ${ }^{29,30}$ The extensor muscle group arises from the anterior surfaces of the fibula and tibia and includes the extensor hallucis longus, extensor digitorum longus, and tibialis anterior. ${ }^{29,30}$ The extensor hallucis longus originates at the middle $1 / 2$ of the fibula as well as partially from the interosseous membrane. ${ }^{29,30}$ It inserts into the dorsal surface of the distal phalanx of the first toe, and acts as a extensor to the IP and MTP joints, and assists in DF. ${ }^{29,30}$ Muscle strength is assessed clinically in plantar flexion with extension of the IP and MTP joints. ${ }^{30}$ The extensor hallucis longus is innervated by the deep peroneal nerve arising from 
$\mathrm{L} 4{ }^{30}{ }^{30} 5$ and $\mathrm{S} 1 .^{29,30}$ The extensor digitorum longus longus extends proximally from the lateral tibial condyle, superior $3 / 4^{\text {ths }}$ of the fibula, as well as the interosseous membrane and fascia. ${ }^{29,30}$ After crossing the ankle joint, it divides into 4 tendons each inserting into the base of the middle and distal phalanges of toes $2-5 . .^{29,30}$ In this orientation, the muscle acts to extend all joints of the toes, MTP, and DF ${ }^{29,30}$ Muscular strength is assessed in plantar flexion with extension of toes 2-5 completed simultaneously. ${ }^{30}$ Innervation for the extensor digitorum longus is the peroneal nerve from roots $L 4{ }^{30} \mathrm{~L} 5$, and $\mathrm{S} 1 .{ }^{29,30}$ The primary extensor of the ankle is the tibialis anterior which arises from the lateral tibial condyle, superior $1 / 2$ of the anterolateral tibia, interosseous membrane, and fascia. ${ }^{29,30}$ It inserts into the medial and volar surfaces of the medial cuneiform bone as well as base of the first metatarsal. ${ }^{29,30}$ In addition to DF, the tibialis anterior aids in inversion. ${ }^{29,30}$ Clinically, strength is assessed in DF and slight inversion. ${ }^{29,30}$ Innervation is supplied by the deep peroneal nerve primarily from $L 4, L 5^{29,30}$ and $S 1 .{ }^{30}$

Eversion of the foot is produced by the peroneal muscle group, of which, the longus and brevis originate on the lateral fibula and the tertius on the anterior fibula. ${ }^{29,30}$ The tertius specifically arises from the inferior $1 / 3$ of the fibula as well as the interosseous membrane. ${ }^{29,30}$ Notably, the tertius shares an origin with the extensor digitorum longus, but functions as an evertor rather than extensor. ${ }^{29}$ Distally, the tertius travels anterior to the lateral malleolus and inserts into the superior surface of the base of the $5^{\text {th }}$ metatarsal. ${ }^{29,30}$ It functions as a evertor and dorsiflexor and is assessed in the same manner. ${ }^{30}$ It is innervated by the deep peroneal nerve, derived from roots $\mathrm{L} 5, \mathrm{~S} 1,,^{29,30}$ and $\mathrm{L} 4 .^{30}$ The origin of the peroneal longus extends from the lateral tibial condyle and the fibular head and $2 / 3^{\text {rds }}$ the length of the lateral surface of the fibula. ${ }^{29,30}$ In contrast to the tertius, the longus travels behind the lateral malleolus through the peroneal groove, under the foot and inserts into the $1^{\text {st }}$ metatarsal and medial cuneiform..$^{29,30}$ It 
functions primarily as an evertor, aiding in $\mathrm{PF} .{ }^{29,30}$ Neural control is provided by the superficial peroneal nerve derived from roots $\mathrm{L} 5, \mathrm{~S} 1,{ }^{29,30}$ and $\mathrm{L} 4 .^{30}$ The peroneal brevis originates inferior to the peroneus longus and inserts into the lateral aspect of the base of the $5^{\text {th }}$ metatarsal. The brevis is innervated along with the longus by the superficial peroneal nerve and nerve roots $L 5$, $\mathrm{S} 1,{ }^{29,30}$ and $\mathrm{L} 4 .^{30}$ The longus and brevis are tested together in $\mathrm{PF}$ and eversion with medial tibial and hip rotation to place the foot in a gravity dependent postion. ${ }^{30}$

The primary flexors of the ankle are the muscles of the triceps surae including the gastrocnemius, soleus, and plantaris. ${ }^{29,30}$ The most prominent of the three, the gastrocnemius, arises from both condyles of the femur. ${ }^{29,30}$ It then inserts into the posterior heel through the calcaneal tendon. ${ }^{29,30}$ The soleus descends from the posterior fibular head, superior $1 / 3^{\text {rd }}$ of the fibula, and the posterior tibia, inserting into the Achilles tendon. ${ }^{29,30}$ The plantaris originates on the distal lateral femur above the condyle, descending to the Achilles tendon. ${ }^{29,30}$ Innervation for the gastrocnemius, soleus, and plantaris is provided by the tibial nerve, primarily through the $\mathrm{S} 1$ and S2 roots. ${ }^{29,30}$

The secondary flexors of the ankle rest deep to the primary flexors. ${ }^{29,30}$ The tibialis posterior originates from the superior posterolateral aspect of the tibia as well as interosseous membrane and posterior fibula. ${ }^{29,30}$ From there it descends, passing posterior to the medial malleolus and inserting into the navicular, all cuneiforms, cuboid, and metatarsals $2-4 .{ }^{29,30} \mathrm{It}$ 's primary action is to invert the foot and secondarily plantarflexes. ${ }^{29,30}$ Strength is assessed clinically by externally rotating the leg to assess against gravity followed by maintaining inversion during plantar flexion. ${ }^{30}$ Neural supply is provided by the tibial nerve desceding from $\mathrm{L} 5$ and $\mathrm{S} 1^{29,30}$ and possibly $\mathrm{L} 4 .^{30}$ Inferomedial to the tibialis posterior origin rests the origin for the flexor digitorum longus, which descends the middle of the posterior tibia as well as the 
interosseous membrane. ${ }^{29,30}$ From their, the muscle travels to posterior to the medial malleolus, diving into 4 tendons and inserting distal to the distal interphalangeal joints of toes $2-5 .{ }^{29,30}$ It is assessed by opposing flexion of the toes in a neutral ankle alignment. ${ }^{29,30}$ Innervation is provided by the tibial nerve ${ }^{29,30}$ with a disputed nerve root derivation from $\mathrm{L} 5, \mathrm{~S} 1$, and $\mathrm{S} 2^{30}$ or $\mathrm{S} 2$ and $\mathrm{S} 3 .^{29}$ The flexor hallucis longus originates more laterally, from the middle to distal posterior fibula. ${ }^{29,30}$ From that position it crosses the posterior ankle, passing posterior to the medial malleolus and traveling to the distal phalanx of the first ray. ${ }^{29,30}$ It is commonly tested by opposing flexion of the interphalangeal joint in some plantar flexion. ${ }^{30}$ As with the flexor digitorum, consensus exists for innervation by the tibial nerve, ${ }^{29,30}$ with dispute of roots $\mathrm{L} 5, \mathrm{~S} 1$, and $\mathrm{S} 2^{30}$ or $\mathrm{S} 2$ and $\mathrm{S} 3 .{ }^{29}$

Riemann and Lephart ${ }^{26}$ thoroughly reviewed the function of mechanoreceptors found in ligaments, tendons, and muscles along with how this information is integrated. In summarizing the data on mechanoreceptors, they ${ }^{26}$ noted golgi tendon organs (GTO) and muscle spindles are the dominant receptors of the musculotendious system. GTOs have been identified as being intermingled within the tendon at varying distances from the musculotendinous junction. ${ }^{26}$ Each GTO surrounds several fibers which are continuous through the length of the tendon. ${ }^{26}$ This configuration enables nervous system feedback as to the amount of tension acting on the tendon of the joint. ${ }^{26}$ GTOs have been classified as being low-threshold and sensitive, enabling them to process minute information, which is then processed in the central nervous system. ${ }^{26}$ By comparison, spindles have been described as located in various locations of the muscle belly. ${ }^{26}$ In these locations, the spindles are able to convey information regarding changes in muscle firing rate and length to the central nervous system. ${ }^{26}$ Spindles are generally specified tissues which identify either length or firing rate changes. ${ }^{26}$ Each spindle contains afferent nerve endings encapsulated with muscle fibers. ${ }^{26}$ 
Riemann and Lephart ${ }^{26}$ further summarized that a greater number of mechanoreceptors are located in ligamentous tissue. It has been reported that ligaments contain 4 types of proprioceptors which have been classified as Ruffini endings, Pacinian corpuscles, GTO-like receptors, and free nerve endings. ${ }^{26}$ In summarizing research Riemann and Lephart classified Ruffini endings as low-threshold, slow adapting receptors which are thought to respond to static postural deviations. Pacinian corpuscles have been described in the literature as low-threshold, fast adapting and are considered to be involved during human function. ${ }^{26}$

With respect to the ankle joint specifically, several researchers ${ }^{14,27,28}$ have investigated the presence of mechanoreceptors in several ligaments of the ankle. They ${ }^{14,27,28}$ used a series of cadaver dissections to count the numbers of the different types of receptors in each ligament. Mechanoreceptors were classified as type I/Ruffini (low-threshold, slow-adapting, static), type II/Pacinian (low, fast, dynamic), type III/Golgi Like (high, slow, dynamic), and type IV/Free Nerve Endings (pain endings). ${ }^{27}$ Michelson and Hutchins ${ }^{27}$ examined the ATF, PTF, CF, and divided the deltoid ligament into superior and deep sections. ${ }^{27}$ This study reported that significantly more type II and type III endings were demonstrated in all of the ligaments than type I, and no type IV endings were observed. ${ }^{27}$ Further, no significant differences were observed in the number of type I endings between different ligaments. ${ }^{27}$ In terms of type II and type III, fewer were observed in the superficial deltoid ligaments than other ligaments and between the CF and PTF. ${ }^{27}$ Additionally, the distribution of receptors was not significantly related to depth or proximity to boney insertions. ${ }^{27}$ The authors hypothesized that the distribution of mechanoreceptors may be due to large numbers of static, type I receptors being less necessary. ${ }^{27}$ Similarly, Moraes et al. ${ }^{28}$ noted that Pacinian endings were the most prevalent 
receptors in the ATF, CF, and PTF ligaments following histological examination and staining. They did not report a difference of receptor type density between different structures. ${ }^{28}$

In contrast, Rein et al. ${ }^{14}$ reported that Ruffini endings were the second most prevalent fiber type in the ankle joint ligaments after free nerve endings. Further, they ${ }^{14}$ reported that Ruffini endings were the most prevalent in the anterior tibiofibular ligament followed by the lateral ligaments then the ligamentous structures of the sinus tarsi. Ruffini endings were more prevalent than Pacinian corpuscles in every ligament investigated. ${ }^{14}$

\section{Pathologies Associated with Decreased Dorsiflexion}

One previous study ${ }^{19}$ has investigated the effects of sustaining an injury on various measures of DF. In this investigation, DF was examined in several positions including: seated with straight knee, prone with bent knee, weight-bearing straight knee, and weight-bearing flexed knee. ${ }^{19}$ None of these measures was significantly different between ankles. ${ }^{19}$ Additionally, Denegar et al. ${ }^{19}$ investigated the intraclass correlation (ICC) of the different measures. Each measure had a high ICC, however, the highest was determined to be standing, bent knee for the injured ankle (.99) and standing straight knee for the uninjured ankle (.99). ${ }^{19}$ Denegar et al. ${ }^{19}$ reported no significant differences between non-injured and post-injured ankle DF. All subjects in this study had an ankle sprain within the previous six month period. ${ }^{19}$

It has been reported that humans need at minimum $10^{\circ} \mathrm{DF}$ ROM in order to ambulate properly. ${ }^{18}$ Limited DF has been identified as a risk factor for injury to ankle $e^{1,2}$ and knee. ${ }^{31}$ In a prospective study, researchers examined to what extent limited dorsiflexion impacts the risk of sustaining a ankle ligament sprain. ${ }^{1}$ These investigators examined various ROM, strength, and static positions for the foot, ankle, and hip; and determined that, of these, only extended knee DF was significant. ${ }^{1}$ This investigation examined these factors in a sample of 241 subjects, of 
whom, 44 sustained 1 or more ankle sprains, and 108 sustained no injury at all to the lower extremity. ${ }^{1}$ It should be noted that these investigators only examined male freshman college level athletes, but conducted the investigation over a period of 3 years. ${ }^{1}$ The demographic characteristics of the sample prove to be a limitation of the study as it has a decreased amount of external validity. ${ }^{1}$

By comparison, a cross-sectional investigation on the association of DF and any ankle injury indicated that those who had sustained a lower extremity injury had lower contralateral ankle dorsiflexion than control subjects. ${ }^{2}$ The control group consisted of subjects who presented to the clinic with an upper extremity injury, and no differences in this group were found between left and right ankles for DF. ${ }^{2}$ For this reason, the authors felt confident in their decision to use the contralateral ankle DF as a predictor of injury. ${ }^{2}$ The contralateral ankle of the injured group had significantly less motion than control subjects for both flexed knee and straight knee DF. ${ }^{2}$ Notably, the injured group had approximately half the dorsiflexion of the uninjured group. ${ }^{2}$ Furthermore, the difference in motion observed continued to be significant following age and gender adjustment. $^{2}$

Other prospective studies ${ }^{8,32,33}$ demonstrated a lack of significance of DF ROM between injured and un-injured subjects. Baumhauer et al. ${ }^{32}$ Described that dorsiflexion was not different between injured and uninjured subjects while comparing male and female college athletes from several sports. They noted that this lack of difference was evident regardless of measuring DF in knee extension or knee flexion. ${ }^{32}$ This study reported that of 145 subjects, 15 sustained injury. ${ }^{32}$ The difference noted between the sample size and number of injuries in this study ${ }^{32}$ and Willems et al. ${ }^{1}$ could help explain some of the differences in significance. Further, the differences in Willems et al. ${ }^{1,33}$ is potentially related to a greater mean DF in women, causing 
this study to not demonstrate a relationship. Additionally, de Noronha et al. ${ }^{8}$ did not observe any relationship between dorsiflexion and injury risk. It should further be noted that de Noronha et al. $^{8}$ reported larger dorsiflexion values $\left(43.9^{\circ}\right)$ than any of the other researchers. ${ }^{1,2,31,32}$

With respect to knee injuries, weight bearing DF was reported to be a significant indicator of risk for patellar tendinopathy. ${ }^{31}$ Backman and Danielson ${ }^{31}$ performed a prospective examination on 75 elite amateur subjects over a 1 year period. They ${ }^{31}$ assessed dorsiflexion at baseline by using a bent knee-weight bearing technique. This investigation determined that decreased dorsiflexion at baseline was significantly related to the development of patellar tendinopathy within the next year. ${ }^{31}$ This significance was noted for both injury to the dominant and non-dominant leg. ${ }^{31}$ Furthermore, the authors ${ }^{31}$ determined that the optimal ROM to reduce incidence of patellar tendinopathy was $36.5^{\circ} .^{31}$

In addition to the pathologies previously mentioned, DF has been associated with diminished performance on Star Excursion Balance Test (SEBT) in chronically unstable ankles. ${ }^{3,4}$ Bassnett et al. ${ }^{3}$ reported a weak to moderate correlation between DF measures and normalized reach distances of the SEBT. Basnett et al. ${ }^{3}$ noted that especially the anterior direction of the SEBT was correlated with limited DF. For this investigation DF was measured by having the subject maintain a flat footed posture with the testing foot posterior to the subject. ${ }^{3}$ In this position, a digital inclinometer was positioned over the tibia in order to give the angle of the tibia against a horizontal reference. ${ }^{3}$ Furthermore, the authors ensured to have slight knee flexion. ${ }^{3}$ For this study, chronic instability was defined as one or more ankle sprains and the sensation of giving way on multiple occasions. ${ }^{3}$ Similarly, in a separate study of CAI, Hoch et al. ${ }^{4}$ found that weightbearing DF ROM as measured as distance from the knee to the toes was moderately correlated with anterior component of the SEBT. For this investigation, ${ }^{4}$ the knee 
was stabilized against a wall and ankle DF was measured similar to that reported by Denegar et

al. ${ }^{19}$ No significant correlations were observed for posterolateral or posteromedial components. ${ }^{4}$ Furthermore, it should be noted that Hoch et al. ${ }^{5}$ have similarly reported that DF ROM is correlated with SEBT performance in healthy subjects.

\section{Pathologies Associated with Decreased Postural Control}

Several prospective clinical trials ${ }^{34-39}$ have investigated the effectiveness of preventing injuries by performing balance training. All studies reported significantly fewer injuries in balance training groups compared to control comparisons. ${ }^{34-37}$ Two of the studies ${ }^{34,35}$ evaluated the balance and neuromuscular training in young adults of both genders, while other studies $^{36,37,39}$ examined the usefulness in a sample of adolescents. Reported odds ratios for the three investigations vary from 0.33 to 0.56 , indicating a protective effect of training. ${ }^{34-36}$

Several studies ${ }^{34,36,37}$ reported the incidence rate of injuries per 1000 exposures and the other ${ }^{35}$ reported injuries per 1000 hours. The investigations reporting injury per exposures noted 1.53 versus $4.31,^{34} 1.13$ versus $1.87^{36}$ and 0.5 versus $2.2^{37}$ injuries per 1000 exposures in the treatment and control groups respectively. It should be noted that McGuine and Keene ${ }^{36}$ reported approximately 5 times the number of exposures as Eils et al. ${ }^{34}$ The investigation describing injury per hours, ${ }^{35}$ noted a smaller incidence rate of 0.5 versus 0.9 . This difference should not be surprising as each exposure will commonly last longer than one hour. Dissimilarly from other research, Tropp et al. ${ }^{38}$ reported that the percentage of athletes who sustained injuries during a season was less in the balance treatment group than in controls. They observed that $5 \%$ of subjects in the training group suffered from an ankle sprain versus $17 \%$ in the control group. $^{38}$ 
Other prospective studies on the injury predictive ability of the SEBT indicated that decreased performance was indicative of risk of injury. ${ }^{6-8}$ Plisky et al. ${ }^{6}$ conducted a linear regression of injury risk associated and anterior, posteromedial, and posterolateral SEBT components, with normalization to leg length. This study, which examined over 200 high school basketball athletes, additionally controlled for previous injury, injury prevention training, gender, grade level, and tape or bracing. ${ }^{6}$ Statistically significant odds ratios for the anterior direction were observed for deficits of $4 \mathrm{~cm}$ difference in anterior reaching between legs and less than $84.3 \%$ normalized length for the right leg. ${ }^{6}$ In the posteromedial direction, less than $109 \%$ for the right leg and $108.7 \%$ were significant. ${ }^{6}$ Similarly for posterolateral, less than $105.6 \%$ for the right leg and $105.5 \%$ for the left were significant. In normalized combination of all directions, less than $94.0 \%$ for the right leg and $95.6 \%$ for the left leg were significant. ${ }^{6}$ Further, the composite SEBT demonstrated the largest odds ratios for right (2.8) and left (2.4) legs. ${ }^{6}$

Butler et al. ${ }^{7}$ used an instrumented measure of SEBT balance to quantify injury risk. They observed that subjects who scored below $89 \%$ leg length for the composite average of anterior, posteromedial, and posterolateral were at 3.5 times greater risk of injury. ${ }^{7}$ This test was performed by summing the maximum value of each of each reach direction, normalizing to leg length, then averaging to number of directions. ${ }^{7}$ This investigation ${ }^{7}$ did not separate risk factor by assessing different prediction related to multiple directions as the previous study by Plisky et al. ${ }^{6}$ did. Finally, Butler et al. ${ }^{7}$ indicated that the cutpoint of $89 \%$ represented a strong sensitivity of $100 \%$ and specificity of $71.7 \%$.

de Noronha et al. ${ }^{8}$ also performed an investigation on multiple risk factors for ankle injury, however, they conducted this investigation in recreationally active subjects at a university. In this investigation, they observed that the posterolateral SEBT and previous ankle 
injury were the only predictive variables for prospective ankle injury at a 1 year follow up. ${ }^{8}$ It is especially interesting to note that neither the anterior or posteromedial direction of the SEBT were considered meaningful predictors in their model. ${ }^{8}$ Specifically, they observed that increased posterolateral reach was protective of ankle injury and the risk ratio was $0.96{ }^{8}$

Steffen et al. ${ }^{9}$ subsequently conducted a cluster randomized investigation to examine the effects of a neuromuscular warm up on injury rates. They reported that high adherence to the training regimen decreased injury rates and improved SEBT performance among adolescent, female, soccer athletes. ${ }^{9}$ Specifically, SEBT improved for left side ANT by $3 \mathrm{~cm}, \mathrm{PM} 4.8 \mathrm{~cm}, \mathrm{PL}$ $3.5 \mathrm{~cm}$; and right side PM $4 \mathrm{~cm}$ and PL $4.5 \mathrm{~cm} .{ }^{9}$ Furthermore, high adherence to the injury prevention program had a protective effect on injury risk (OR $0.28, \mathrm{Cl}=0.10-0.79)$ compared to medium adherence. ${ }^{9}$ No significant effect on injury risk was observed between high adherence and low adherence (OR 0.32, $\mathrm{Cl}=0.14-1.49) .{ }^{9}$ Group assignment was found to improve left and right ANT SEBT for Regular and Comprehensive groups. ${ }^{9}$ Group assignment was separated into control with only access to the online material, regular group received formal instruction, and comprehensive received instruction and were monitored to ensure proper application. ${ }^{9}$

Numerous studies have investigated how chronic ankle instability impacts static balance. ${ }^{40-46}$ Most of these studies utilized forceplates to record Center of Pressure (COP), Time to Boundary (TTB), and Time to Stabilization (TTS) ${ }^{40-45}$ Two studies reported differences in multiple static measures. ${ }^{40,41}$ Two studies reported differences in COP only. ${ }^{42,43}$ One study reported differences in TTB only. ${ }^{44}$ One study reported differences in TTS only. ${ }^{45}$ The one study not using COP measures, investigated Balance Error Scoring System (BESS) scores.

Hertel and Olmstead-Kramer ${ }^{40}$ examined multiple TTB and COP measures. Of the TTB measures almost all were significant. ${ }^{40}$ They noted that the one TTB measure not significant was 
TTB minimum in anterior-posterior (AP). ${ }^{40}$ All other TTB minima, mean, and standard deviation for AP and mediolateral $(\mathrm{ML})$ were significant and had moderate to large effect sizes. ${ }^{40}$ Conversely, the chronic ankle instability group had only 1 COP significant, large difference, which was COP AP velocity. ${ }^{40}$ No other COP measure was significant. ${ }^{40}$ This investigation studied these measures in young female adults, which limits the external validity of this study. ${ }^{40}$ Similarly, Pope et al. ${ }^{41}$ reported that COP and TTB were different in anterolateral and posteromedial directions for eyes opened conditions. In eyes closed conditions, COP and TTB were both significantly different in anteromedial, anterolateral, posteromedial, and posterolateral directions. ${ }^{41}$ Results of this study should be read with caution as the authors analyzed each variable with independent t-tests, without correction. ${ }^{41}$ Further, the authors did not assess for an interaction between chronic ankle instability and eyes closed conditions, which could have been invaluable information. ${ }^{41}$

Of the two studies which only investigated COP, Nakagawa et al. ${ }^{42}$ reported total COP displacement only, whereas, Sefton et al. ${ }^{43}$ noted multiple COP components. Nakagawa et al. ${ }^{42}$ reported significant differences between groups, which each had 19 subjects. Sefton et al., ${ }^{43}$ however, only observed differences in COP ML displacement and velocity as well as COP AP velocity without comparing total COP displacement. The authors, further, reported that COP AP displacement was significant, however, the $p$ value was $0.056 .{ }^{43}$ The combination of significant $M L$ and near significant AP displacements in this study ${ }^{43}$ could indicate consistency with Nakagawa et al. ${ }^{42}$ The two studies ${ }^{42,43}$ had similar group sample sizes. The additional measurement of COP velocities of Sefton et al. ${ }^{43}$ further demonstrated decreased static postural control in chronic ankle instability. 
The sole study ${ }^{45}$ which investigated TTS also examined COP measures, but found none to be significant. Specifically, the only TTS measure which was significant was in the AP direction, which had a moderate effect size. ${ }^{45}$ These authors ${ }^{45}$ chose to study chronic ankle instability in recreation, rather than competitive, athletes, which could contribute to the differences seen between this study and others. ${ }^{40-43}$

McKeon and Hertel ${ }^{44}$ studied several TTB measures in both eyes open and eyes closed conditions. In this study, no significant findings were reported for eyes open, however, several significant, moderate effect findings were reported in eyes closed. ${ }^{44}$ The significant measures included ML minimum, AP minimum, AP mean, and AP standard deviation. ${ }^{44}$ This study recruited 32 subjects for each group, which were then matched for gender and injured side. ${ }^{44}$

The lone study involving BESS measurements reported differences between chronically unstable and healthy ankles for 3 conditions. ${ }^{46}$ The BESS test involves standing on firm and foam surfaces in double leg, singe leg, and tandem position with hands on hips. ${ }^{46}$ Any deviation from upright stance in this position has been counted as an error. ${ }^{46}$ The 3 significant conditions in this investigation were single leg firm, tandem stance foam, and single leg foam. ${ }^{46}$ The researchers defined chronic ankle instability as one or more ankle sprains combined with the sensation of the ankle giving way. ${ }^{46}$

The SEBT has been used as a measure of dynamic balance following ankle injury. ${ }^{42,43,47,48}$ Olmstead et al. ${ }^{47}$ reported that mean reach distances of the SEBT were significantly less for chronically unstable ankles than for stable ankles. This difference was noted for both the subjects' healthy ankles and for a matched control group. ${ }^{47}$ An additional study by Hertel et al. ${ }^{48}$ observed that anteromedial, medial, and posteromedial directions were significantly different between chronic ankle instability and control conditions. For this reason, 
the authors suggest reducing the SEBT to these 3 directions. ${ }^{48}$ Conversely, both Nakagawa et al. ${ }^{42}$ and Sefton et al. ${ }^{43}$ reported that SEBT performance was not significantly limited in subjects with chronic ankle instability. Three studies ${ }^{42,43,47}$ had similar sample sizes of roughly 20 participants per group. Hertel et al., ${ }^{48}$ however, had much larger groups, this could have contributed to the difference in significance seen in this study than in others. ${ }^{42,43}$ Even if the sample size used in Hertel et al. ${ }^{48}$ explains some of their findings, it does little to explain the significance seen in Olmstead et al. ${ }^{47}$

\section{Joint Mobilizations}

Relatively few primary sources exist discussing the indications and contraindications for joint mobilization. Previous authors have discussed the differences between grades of mobilization. ${ }^{20,49}$ In general, grades I and II are designated for relief of pain and spasm, whereas, grades III and IV are used primarily for improving restricted ROM. ${ }^{20,49}$ Grade V mobilization, or manipulation, is reserved for a limitation to the very end of the capsular glide and is generally performed by only those who are specially trained. ${ }^{20,49}$ Grade I mobilization has involved a low velocity small amplitude mobilization at the beginning of the accessory motion. ${ }^{20,49}$ Grade II has been said to involve a larger amplitude mobilization through the midrange of the available accessory motion. ${ }^{20,49}$ Grade III mobilizations have been classified as beginning in the middle of the available accessory motion to the point of restriction..$^{20,49}$ Grade IV mobilizations have been suggested to involve a small amplitude thrust at the end of the accessory motion to the point of restriction. ${ }^{20,49}$

Reported precautions for mobilization have included hypermobility ${ }^{50}$ and several long term orthopedic conditions such as inflammatory arthritis, malignancy, congenital deformities, recent fractures, and bone diseases. ${ }^{20}$ Other orthopedic conditions which are contraindications 
for mobilization include ligament rupture, herniated discs with nerve root compression, and the presence of joint effusion. In any of these conditions, mobilizations could result in increasing the severity of the disease. ${ }^{20}$ Additionally, if pain is felt, during assessment for mobilization or treatment, prior to reaching the point of resistance, the mobilization should be continued with caution. ${ }^{20,49}$ Additional precautions for mobilization include pregnancy, influenza, total joint replacement, severe scoliosis, poor overall health, and a patient not being able to relax. ${ }^{50}$

Several recent studies have examined the use of anterior to posterior talocrural mobilizations on improving DF in acute injury ${ }^{10,22}$ and chronic ankle instability ${ }^{11,12}$. Additionally, research has examined the benefits of joint mobilization on prolonged immobilization ${ }^{13}$ and elderly women. ${ }^{51}$ Results of these studies have been mixed with some reporting significant improvements in $\mathrm{ROM}^{10-13}$ whereas other studies ${ }^{22,51}$ did not see these benefits.

The study by Cosby et al. ${ }^{22}$ investigated acute effects of Maitland Grade III mobilization on DF as well as posterior talar translations and self reported measure of ankle function. The participants of this study all had a recent ankle sprain with brief immobilization ${ }^{22}$. In this investigation, no significant differences were observed at post intervention or 24 hours after treatment ${ }^{22}$. This may be due to a small sample size for the treatment ( 9 subjects) and control ( 8 subjects) groups and poor observed power. Similarly, another study ${ }^{51}$ comparing joint mobilization to sham conditions failed to report significance in elderly subjects. This study ${ }^{51}$ enrolled slightly larger sample sizes (16 subjects per group) than Cosby et al. ${ }^{22}$ In contrast, Hoch and McKeon ${ }^{12}$ utilized a cross-over design allowing more subjects for each condition and reported significant differences between mobilization and control groups. Like Hoch and McKeon, ${ }^{12}$ Landrum et al. ${ }^{13}$ utilized a cross-over design and reported significant effect of using joint mobilizations. Similar to Cosby et al., ${ }^{22}$ however, Landrum et al. ${ }^{13}$ had a small sample size 
(10 subjects). In further consideration of the inconsistent results between studies, Cosby et al. ${ }^{22}$ reported a small effect size. Unfortunately, effect size was not reported by Landrum et al., ${ }^{13}$ but can be easily estimated for Hoch and McKeon ${ }^{12}$ by extracting data. A trivial effect size $(d=0.14)$ for this study ${ }^{12}$ can be observed by calculating (Treatment Mean - Control mean)/Control standard deviation. ${ }^{21}$

Additionally, differences in DF results between the studies ${ }^{12,13,22}$ may be due to measurement differences. Hoch and McKeon ${ }^{12}$ as well as Landrum et al. ${ }^{13}$ assessed passive DF ROM whereas in Cosby et al. ${ }^{22}$ subjects performed an active DF motion in a seated position. The different method used by Cosby et al. ${ }^{22}$ could result in confounding variables not studied impacting the DF measure. The measurement technique they describe does not control for muscle length of the two joint plantar flexor muscles because of knee extension ${ }^{22}$. Additionally, an active DF ROM measurement is dependent upon the strength of the dorsiflexors, especially the tibialis anterior. ${ }^{30}$ The two studies ${ }^{12,13}$ assessing passive DF were also not consistent in that one measured open chain DF and the other closed chain DF. Naturally, the investigation reporting closed-chain bent leg DF demonstrated greater DF than the investigation on openchain straight knee DF. ${ }^{12,13}$

Somewhat paradoxically, the differences seen in results do not appear to be related to treatment time, number of sets per treatment, or number of repetitions per set in single session treatments. ${ }^{12,13,22}$ In all three studies, ${ }^{12,13,22}$ mobilizations were performed at about one repetition per second. Two of these investigations ${ }^{13,22}$ employed a single 30 second set of mobilizations, whereas, Hoch and McKeon ${ }^{12}$ used a 2 sets of 50 repetitions treatment protocol. This could help explain some of the more statistically significant findings between Hoch and 
McKeon ${ }^{12}$ and Cosby et al., ${ }^{22}$ but does little for explaining the differences between Landrum et al. $^{13}$ and Cosby et al. ${ }^{22}$

Prospective clinical trials into the effects of mobilizations on dorsiflexion has been limited, with only 1 study ${ }^{10}$ published. Green et al. ${ }^{10}$ reported that mobilizations resulted in a significantly shorter recovery of normal, pain free DF than RICE alone. In this study, fewer than half of participants needed more than 3 treatment sessions to regain full motion. ${ }^{10}$ A potential limitation of this study is that the authors treated the subjects with grade II mobilizations rather than a grade III mobilization, which may have resulted in an even faster recovery. ${ }^{20}$ An additional limitation of the study would be that the authors ${ }^{10}$ used a seated, knee extended position to assess DF, similar to Landrum et al. ${ }^{13}$

Of somewhat less quality than Green et al., ${ }^{10}$ Hoch et al. ${ }^{11}$ examined the effects of 2 weeks, 6 sessions, of mobilizations on DF. This study was very much limited by a lack of a true control group, instead using 2 separate 1 week sessions before and after treatment. ${ }^{11}$ Hoch et al. ${ }^{11}$ utilized grade II and III mobilizations and 6 sessions for every treatment individual. Following this treatment, DF was significantly greater than baseline and pretesting. ${ }^{11}$ Additionally, this difference persisted for 1 week following the completion of the treatment. ${ }^{11}$ While the authors reported numerous measures of DF effect size as being large $(g>0.70)$, computing effect size values similar to Cosby et al. ${ }^{22}$ reveals a smaller effect size $(d=0.35-0.38) .{ }^{11}$ This investigation ${ }^{11}$ also utilized a greater quantity of oscillations than previous authors have used. ${ }^{10,12,13,22,52-54}$ It is possible that greater amounts of oscillations and multiple treatment sessions could have interacted to result in the increases in DF ROM seen in the present study. ${ }^{11}$ It is important to note that the accumulation of these studies ${ }^{11-13,22,52-54}$ have begun to establish a dose response of joint mobilizations on improving DF. 
Additional, lower-quality investigations ${ }^{52-54}$ have also demonstrated increases in DF ROM. Venturini et al. ${ }^{52}$ and De Souza et al. ${ }^{53}$ made simple pretest to posttest comparisons. In both studies a statistically significant difference was observed following a single session of mobilization. ${ }^{52,53}$ While De Souza et al. ${ }^{53}$ had a slightly improved methodology by testing a control ankle, using separate dependent t-tests for the treatment and non-treatment ankle was not the most appropriate statistical test. Reporting the differences between the treatment posttest and the control posttest would have been valuable. ${ }^{53}$ Estimation of effect size from the authors reported means and baseline standard deviations indicated a small $(d=0.24)^{53}$ to moderate $(d=0.51)^{52}$ effect.

In a case series by Seiger and Draper, ${ }^{54}$ no inferential statistics were performed. In all four cases, however, a trend existed from improving from a condition of hypomobility towards normal mobility. ${ }^{54}$ Generalizability of this result is difficult as the authors did not solely perform mobilizations to the ankle. ${ }^{54}$ While this investigation has clinical value in that mobilizations should not be performed without additional stretching and strengthening, ${ }^{49,55}$ it cannot be determined which therapy induced the change.

Several investigations have examined the benefit of anterior to posterior talar mobilizations in increasing posterior translatory motion. ${ }^{12,13,22}$ In each study, no significant difference was found following a single session of joint mobilization. ${ }^{12,13,22}$ Large similarities existed between these three studies in methodology allowing easy comparison. ${ }^{12,13,22}$ In all three cases, posterior talar motion was assessed by ankle arthrometry. ${ }^{12,13,22} \mathrm{~A}$ posteriorly directed $170 \mathrm{~N}$ force was applied to the talus with the tibia in a stationary position in each study. ${ }^{12,13,22}$

In a prospective investigation of posterior talar mobility and stiffness, Hoch et al. ${ }^{15}$ reported no significant differences as a result of 2 weeks of grade II and III joint mobilizations on 
subjects with chronic ankle instability. This investigation also did not compare a treatment group to a control, instead performing a time series analysis and comparing results to minimal detectable change (MDC) scores. ${ }^{15}$ Regarding the comparison the treatment to the MDC values, the results 1 week following the conclusion of the mobilization treatment were roughly equivalent to the MDC. ${ }^{15}$ Similarly, immediate following the conclusion of the treatment period the results for posterior stiffness surpassed the MDC. ${ }^{15}$ While several of the time points measured also reached a moderate effect size, since none of these results reached significance, it cannot be stated with any certainty that these results were not due to random chance. ${ }^{15}$

Recently, some research has investigated the effects of articular mobilization on self reported questionnaires of ankle function. ${ }^{22}$ In this study, both the treatment and control groups reported similar improvements in activities of daily living and ankle function over time. ${ }^{22}$ In this study, self reported sport specific function was neither affected by time or by the treatment condition at a 24 hour follow up. ${ }^{22}$

In a longer study and follow up period, Hoch et al. ${ }^{11}$ reported that self-reported measures of ankle function were increased following grade II and III mobilization. This was evident immediately following 2 weeks mobilization and sustained for at least 1 week following the treatment. ${ }^{11}$

Recent research into the effects of joint mobilizations on levels of pain has indicated a statistically significant reduction in pain following joint mobilization. ${ }^{22}$ Cosby et al. ${ }^{22}$ reported that 24 hours following a single 30 oscillation session of joint mobilizations, subjects with an acute ankle injury had $20 \%$ less pain than at baseline. ${ }^{22}$ The statistical test for this comparison revealed a main effect for time only and a time $x$ group interaction. ${ }^{22}$ This may be related to a 
possible difference in the baseline values for pain between the two group measures, which was not investigated. ${ }^{22}$

Further research into the pain relieving effects of mobilizations have examined animal models. ${ }^{56-58}$ In one study by Martins et al., ${ }^{56}$ research indicated that grade III joint mobilizations alleviated multiple types of pain in a rat model of pain. Specifically, they demonstrated that pain associated with crushing of sciatic nerve, mechanical pain to the paws, and cryogenic pain were all relieved individually and in combination. ${ }^{56}$ This alleviation of pain persisted through the 35 day test period due to continued administration of mobilizations. ${ }^{56} \mathrm{~A}$ separate report by Martins et al. ${ }^{57}$ examined the ameliorative effect of mobilizations on surgical incision induced pain. This study using grade III mobilizations also indicated that joint mobilizations have a significant effect on reducing levels of a mechanical pain response. ${ }^{57}$ Further, Martins et al. administered an Adenosine A1 blocker which eliminated the ameliorative effect, indicating a serotonin or norepinephrine cause for pain control. ${ }^{57} \mathrm{~A}$ third investigation by Martins et al. ${ }^{58}$ indicated that a decrease in pain secondary to surgery was greater with 9 minutes of joint mobilization than with only 3 minutes of mobilization. Additionally, this investigation determined that the improvements seen with 9 minutes of joint mobilization were reduced by administration of opioid receptor antagonist. ${ }^{58}$ This result was consistent in cases of systemic and local opioid antagonist application. ${ }^{58}$ While endogenous opioid pain control could have contributed to the observed pain relief, chemically blocking opioid controlling leukocytes was not affective at reducing pain relief. ${ }^{58}$

\section{Functional Mobilizations}

To date, no previous research has been conducting evaluating the effectiveness of Functional Manual Reaction. The developers of this technique have provided information 
regarding the technique, however. ${ }^{16,17}$ The techniques they describe for improving ankle dorsiflexion involve standing in a weight bearing lunge position and perform a submaximal lunge ${ }^{16,17}$ For improving dorsiflexion with calcaneal eversion, they suggest standing with the treatment ankle forwards in a lunge stance. ${ }^{16}$ The clinician will anteriorly mobilize and internally rotate the leg and apply a posterior glide to the fibula with respect to the tibia during the mobilization while facilitating a calcaneal everted position. ${ }^{16}$ In order to treat the patient focussing on dorsiflexion and calcaneal inversion the patient will stand with the treatment ankle posteriorly. ${ }^{16}$ The clinician will apply an anterior mobilization and external rotation of the leg while facilitating a calcaneal inverted position. ${ }^{16}$ These treatments necessitate proper lunge technique including knee flexion and hip extension and can involve an overhead motion of the opposite hand to supplement the rotational motions. ${ }^{16}$

While no investigations have examined the indications and contraindications of mobilization with movement (MWM), Mulligan ${ }^{59}$ has described these in brief. Muligan ${ }^{59}$ noted that indications and contraindications were largely similar to those of typical mobilizations. This was due to MWM being a type of joint mobilizations. ${ }^{59}$ It was presented that in addition to other contraindications, MWM should not be performed when the patient experiences pain with motion combined with a glide..$^{59}$

In addition to joint mobilizations, MWM has been investigated for increasing DF in subjects with prior ankle sprains. ${ }^{23-25}$ Each study indicated a statistically significant difference following a single session of MWM. ${ }^{23-25}$ Additionally, each of these studies measured DF as the furthest distance the heel was rested from a wall while maintaining the knee against the wall. ${ }^{23-}$ ${ }^{25}$ Reid et al. ${ }^{23}$ conducted a double blind cross over investigation which indicated greater improvements in DF following MWM than sham treatment and extracting data from their study 
reveals an effect size of approximately $d=0.16$. In this investigation, the treatment condition was performed in 2 sets of 10 repetitions with 2 minutes rest. ${ }^{23}$ This was different from Vicenzino et al. ${ }^{24}$ who used a protocol of 4 sets of 4 mobilizations in each set. Each subject was then given 20 seconds of rest between sets. ${ }^{24}$ Vicenzino et al. ${ }^{24}$ used a cross-over method to investigate the difference between control and weight bearing and non-weightbearing MWM procedures. The authors noted that from pre to post treatment, significant differences existed for all three conditions but noted that both treatments had a larger effect size $(d=0.3-0.4)$ than the control $(d=0.1)$. Similarly, Collins et al. ${ }^{25}$ utilized a cross over design with placebo and control.

Unfortunately, Collins et al. ${ }^{25}$ did not report whether differences existed between conditions. Data extracted from Collins et al. ${ }^{25}$ revealed a slightly smaller effect size for MWM than reported in Vicenzino et al. ${ }^{24}(\mathrm{~d}=0.28)$.

Only one investigation ${ }^{24}$ examined the effects of MWM on posterior talar glide mobility. Vicenzino et al. ${ }^{24}$ examined posterior talar glide as a clinical measure as described by Denegar et al. ${ }^{19}$ rather than as a measure of arthrometry. In this case, Vicenzino et al. ${ }^{24}$ found a significant, large difference in posterior talar translatory motion following both types of MWM. The control group, while significantly different from baseline, resulted in only a trivial effect size at posttest. ${ }^{24}$ No significant differences were noted between the weight-bearing and non-weightbearing MWM and both had a large effect size $\left(d=0.9,0.8\right.$ respectively) ${ }^{24}$

The effect size reported in Vicenzino et al. ${ }^{24}$ is larger than what has been previously reported with joint mobilization techniques. ${ }^{12,13,22}$ It is possible that this could indicate that MWM in this study ${ }^{24}$ are superior to joint mobilization in this regard, but at this time, this cannot be determined due to non-significant effect of joint mobilizations. ${ }^{12,13,22}$ Unfortunately, the 
relationship between the clinical measure for posterior talar mobility and the arthrometric has not been established so a direct comparison may not be appropriate.

To date, only one investigation has examined how MWM has affected pain levels. ${ }^{25}$ In this investigation, the authors ${ }^{25}$ performed pretest and posttest examinations on subjects in either a MWM, placebo, or control condition based on temperature and mechanical pressure. No significant differences in pain detection were reported at the ATF or CF ligaments or the tibialis anterior locations. ${ }^{25}$

\section{Methods of Improving Postural Control}

Eils et al. ${ }^{34}$ reported that no differences were observed in the control group for any COP measure. In the treatment group, however, maximum and standard deviation of ML sway as well as total postural sway were different. ${ }^{34}$ All subjects in this investigation were healthy at the outset of the study. ${ }^{34}$ This study involved both static and function forms of balance tasks on several surface types including single leg balance, balance beam, wobble board, and jumping on pliable surfaces. ${ }^{34}$ No indication was given as to the duration of the training protocol. ${ }^{34}$

Eils and Rosenbaum ${ }^{60}$ reported that biomechanical measures of balance were significantly different following 6 weeks of neuromuscular exercise. This investigation was conducted on chronically unstable ankles. ${ }^{60}$ They $^{60}$ observed that maximal and standard deviation of $M L$ postural sway was reduced following training but not seen in control subjects. Also notable was the observance that both groups demonstrated decreased total COP sway. ${ }^{60}$ Anteroposterior postural sway was not different following training, but was different in control subjects at follow up. ${ }^{60} \mathrm{~A}$ variety of exercises were performed on several surfaces including foam, air disk, wobble boards, and Biodex systems in this investigation. ${ }^{60}$ 
McKeon et al. ${ }^{61}$ investigated the effects of 4 weeks balance training on static balance in unstable ankles. These authors ${ }^{61}$ did not observe any differences between groups following balance training in TTB measures during eyes open balance. ${ }^{61}$ Absolute and mean minimum TTB ML, mean minimum TTB AP, and TTB AP standard deviation in eyes closed testing demonstrated time and group differences. ${ }^{61}$ Furthermore, of all eyes open and closed measures of COP, only eyes closed ML COP velocity was significantly different following training. ${ }^{61}$ Training in this investigation involved multiple hop exercises with stabilization after landing as well as single leg stance on hard and foam surfaces, with and without a ball toss, and with eyes closed and eyes open. $^{61}$

As opposed to previously mentioned studies, a study by Verhagen et al. ${ }^{62}$ did not find any significant differences between groups or over time following $5 \frac{1}{2}$ weeks of training.

Additionally, no group differences were observed in either eyes open or closed conditions. ${ }^{62}$ This investigation used balance tasks on several surfaces with perturbations imposed by spiking or throwing balls. ${ }^{62}$ No types of dynamic balance were used in this investigation. ${ }^{62}$ Each group in this study had 11 or fewer participants, which could have been an inadequate sample size for the study. ${ }^{62}$ The groups consisted of a volleyball group with intervention, a non-active intervention group, and a control. ${ }^{62}$

A somewhat longer investigation, evaluating the effects of 8 weeks balance training on stable and unstable surfaces reported that postural sway was improved compared to a control group. ${ }^{63}$ This investigation used a NeuroCOM testing device which allows for an assessment of postural sway both on a stable surface and in an unstable condition. ${ }^{63}$ The treatments involved varying degrees of difficulty involving balancing on a hard or unstable surface with and without a ball toss. ${ }^{63}$ 
Separately from other investigations which used multiple surface types and conditions, Lee and $\operatorname{Lin}^{64}$ conducted research on single leg balance on a BAPS board. Treatment in this investigation involved 12 weeks of progressively increasing training involving maintaining level balance and performing circles on the balance board. ${ }^{64}$ This training was conducted in subjects who had functionally unstable ankles, which had decreased balance ability at the outset of the study compared to healthy ankles. ${ }^{64}$ Testing was conducted on a force platform and expressed as radius of COP. ${ }^{64}$ Following training, balance measures were significantly improved in the functionally unstable ankle. ${ }^{64}$

Additional studies investigated the effects of proprioceptive training on dynamic balance measured by SEBT. ${ }^{61,65}$ Four weeks balance training as previously described has resulted in significant time and group differences in posterolateral and posteromedial directions of a SEBT. ${ }^{61}$ For both directions, a positive moderate time effect size and large group effect size was reported. ${ }^{61}$ Additionally, a comprehensive balance protocol improved reach distances in adolescent female athletes. ${ }^{65}$ Filipa et al. ${ }^{65}$ used a protocol which included single leg balances, lunges, landing stabilizations, and other exercises with variations over 8 weeks. It is important to note that Filipa et al. ${ }^{65}$ had smaller samples than McKeon et al. ${ }^{61}$ but still had significant results. Additionally, unlike McKeon et al., ${ }^{61}$ Filipa et al. ${ }^{65}$ examined a neuromuscular protocol in healthy subjects only.

In addition to these studies, a recent investigation ${ }^{66}$ investigated the immediate effects of instability training on postural sway. They reported instantaneous effects as well as $30 \mathrm{~min}, 1$ hour, 6 hours, and 24 hours following treatment. ${ }^{66}$ The noted at several time points that the experimental group demonstrated significantly improved postural control compared to a control condition. ${ }^{66}$ The treatment that they performed involved multiple static and dynamic balance 
tasks involving a BOSU ball. ${ }^{66}$ Similarly, they ${ }^{67}$ also conducted an investigation using the same treatment technique and assessing two legged stance postural sway. In this investigation, they found that postural sway decreases immediately following a treatment program. ${ }^{67}$

Furthermore, a few researchers have investigated the acute effects of bracing ${ }^{68}$ and taping ${ }^{69,70}$ on performance of the SEBT and/or stabilometric measures. None of these investigations observed differences in performance of the SEBT in any direction. ${ }^{68-70}$ It shoulder be noted that all of these investigations used a cross-over design ${ }^{68-70}$ with two ${ }^{68,69}$ reporting all testing being performed during a single session. The third investigation ${ }^{70}$ did not report whether all testing was completed in a single session or spread over time. All of these studies examined a similar patient population, focussing on subjects with CAI. ${ }^{68-70}$

Four studies have investigated the effects of joint mobilizations on improving balance. $^{11,12,15,71}$ Of these studies, two ${ }^{12,71}$ were conducted following an acute bout of joint mobilization. The third and fourth ${ }^{11,15}$ measured balance twice prior to and twice following 2 weeks joint mobilization treatment. Three of these studies ${ }^{11,12,15}$ were conducted on chronically unstable ankles, while one ${ }^{71}$ was conducted in healthy subjects.

Two weeks of mobilization treatments resulted in significantly greater reach distances on 3 directions of a SEBT test in chronically unstable ankles. ${ }^{11}$ The directions measured for SEBT were anterior, posterolateral, and posteromedial. ${ }^{11}$ This investigation used a design of 4 testing sessions, 2 before and 2 after a period of joint mobilization. ${ }^{11}$ In a similar by Hoch et al., ${ }^{15}$ static balance was not found to be significant following 2 weeks mobilization treatments. This investigation further reported effect sizes as calculated by Hedges g, with several comparisons between the 4 measurement points for eyes open and eyes closed COP range identified as moderate.${ }^{15}$ As stated in an earlier section, since these comparisons should be read with caution 
due to a lack of effect. ${ }^{15}$ Interestingly, an earlier, cross-over investigation by Hoch and McKeon ${ }^{12}$ noted that mean minimum TTB AP and Standard Deviation TTB AP were both significantly increased following posterior joint mobilizations in chronically unstable ankles while SEBT reach distance was unaffected. These results paradoxically report that postural sway improves instantaneously following joint mobilization but is not improved prospectively. ${ }^{11,15}$ Dynamic postural control measured by the SEBT, was, however, improved over time but these results were not evident immediately. ${ }^{11,15}$ Conversely, Laudner et al. ${ }^{71}$ did not find any differences in COP measures in healthy subjects following joint mobilization.

The two cross-over investigations used a similar methodology to assign groups, treat, and assess for static balance. ${ }^{12,71}$ Only Hoch and McKeon ${ }^{12}$ assessed dynamic balance as part of the investigation, which was not significant. Additionally, Laudner et al. ${ }^{71}$ did not assess DF ROM as part of the study, which may have been an important confounder. Furthermore, while both $^{12,71}$ used biomechanical data to assess static balance, different measures were gathered. Hoch and McKeon ${ }^{12}$ assessed TTB data, whereas Laudner et al. ${ }^{71}$ assessed COP range, area, and velocity. 


\section{REFERENCES}

1. Willems TM, Witvrouw E, Delbaere K. Intrinsic predictive factors for ankle sprain in active university students: a prospective study. Br. J. Sports Med. 2005;39(9):689-689.

2. Tabrizi P, Mclntyre W, Quesnel $M$, Howard A. Limited dorsiflexion predisposes to injuries of the ankle in children. J. Bone Joint Surg. Br. 2000;82B(8):1103-1106.

3. Basnett CR, Hanish MJ, Wheeler TJ, et al. Ankle dorsiflexion range of motion influences dynamic balance in individuals with chronic ankle instability. Int. J. Sports Phys. Ther. 2013;8(2):121-128.

4. Hoch MC, Staton GS, Medina McKeon JM, Mattacola CG, McKeon PO. Dorsiflexion and dynamic postural control deficits are present in those with chronic ankle instability. J. Sci. Med. Sport. 2012;15(6):574-579.

5. Hoch MC, Staton GS, McKeon PO. Dorsiflexion range of motion significantly influences dynamic balance. J. Sci. Med. Sport. 2011;14(1):90-92.

6. Plisky PJ, Rauh MJ, Kaminski TW, Underwood FB. Star Excursion Balance Test as a predictor of lower extremity injury in high school basketball players. J. Orthop. Sports Phys. Ther. 2006;36(12):911-919.

7. Butler RJ, Lehr ME, Fink ML, Kiesel KB, Plisky PJ. Dynamic balance performance and noncontact lower extremity injury in college football players: an initial study. Sports Health. 2013;5(5):417-422.

8. De Noronha M, franca L, Haupenthal, A, Nunes G. Intrinsic predictive factors for ankle sprain in active university students: A prospective study. Scand. J. Med. Sci. Sports. 2013;23(5):541-547.

9. Steffen K, Emery C A, Romiti M, et al. High adherence to a neuromuscular injury prevention programme (FIFA 11+) improves functional balance and reduces injury risk in Canadian youth female football players: a cluster randomised trial. Br. J. Sports Med. 2013;47(12):794-802.

10. Green T, Refshauge K, Crosbie J, Adams R. A randomized controlled trial of a passive accessory joint mobilization on acute ankle inversion sprains. Phys. Ther. 2001;81(4):984-994. 
11. Hoch MC, Andreatta RD, Mullineaux DR, et al. Two-week joint mobilization intervention improves self-reported function, range of motion, and dynamic balance in those with chronic ankle instability. J. Orthop. Res. 2012;30(11):1798-1804.

12. Hoch MC, McKeon PO. Joint mobilization improves spatiotemporal postural control and range of motion in those with chronic ankle instability. J. Orthop. Res. 2011;29(3):326332.

13. Landrum EL, Kelln BM, Parente WR, Ingersoll CD, Hertel J. Immediate Effects of Anterior-toPosterior Talocrural Joint Mobilization after Prolonged Ankle Immobilization: A Preliminary Study. J. Man. Manip. Ther. 2008;16(2):100-105.

14. Rein S, Hagert E, Hanisch U, Fieguth A. Immunohistochemical analysis of sensory nerve endings in Ankle ligaments: A cadaver study. Cells Tissues Organs. 2013;197:64-76.

15. Hoch MC, Mullineaux DR, Andreatta RD, et al. Effect of a 2-week joint-mobilization intervention on single-limb balance and ankle arthrokinematics in those with chronic ankle instability. J. Sport Rehabil. 2014;23(1):18-26.

16. Gray G, Tiberio D. Functional Manual Reaction (FMR) The Foot and Ankle. Graylnstitute. Available at: www.grayinstititue.com. Accessed August 23, 2013.

17. Tiberio D. Functional Manual Reaction. Graylnstitute. Available at: www.grayinstitute.com. Accessed August 23, 2013.

18. Magee DJ. Orthopedic Physical Assessment. 5th ed. St. Louis, MO: Saunders Elsevier; 2008.

19. Denegar C, Hertel J, Fonseca J. The effect of lateral ankle sprain on dorsiflexion range of motion, posterior talar glide, and joint laxity. J. Orthop. Sports Phys. Ther. 2002;32(4):166-173.

20. Hengeveld E, Banks K. Maitland's Peripheral Manipulation. 4th ed. London, United Kingdom: Butterworth-Heinemann; 2005.

21. Cohen J. Statistical Power Analysis for the Behavioral Sciences. Revised Edition. Hillsdale, N.J.: Lawrence Erlbaum Associates; 1987.

22. Cosby NL, Koroch M, Grindstaff TL, Parente W, Hertel J. Immediate effects of anterior to posterior talocrural joint mobilizations following acute lateral ankle sprain. J. Man. Manip. Ther. 2011;19(2):76-83.

23. Reid A, Birmingham T, Alcock G. Efficacy of mobilization with movement for patients with limited dorsiflexion after ankle sprain: a crossover trial. Physiother. Can. 2007;59(3):166-172.

24. Vicenzino B, Branjerdporn M, Teys P, Jordan K. Initial changes in posterior talar glide and dorsiflexion of the ankle after mobilization with movement in individuals with recurrent ankle sprain. J. Orthop. Sports Phys. Ther. 2006;36(7):464-471. 
25. Collins N, Teys P, Vicenzino B. The initial effects of a Mulligan's mobilization with movement technique on dorsiflexion and pain in subacute ankle sprains. Man. Ther. 2004;9(2):7782.

26. Riemann B, Lephart S. The sensorimotor system, part I: the physiologic basis of functional joint stability. J. Athl. Train. 2002;37(1):71-79.

27. Michelson JD, Hutchins C. Mechanoreceptors in human ankle ligaments. J. Bone Joint Surg. Br. 1995;77(2):219-224.

28. Moraes M, Cavalcante M, Leite J, Ferreira F, Castro A, Santana M. Histomorphometric evaluation of mechanoreceptors and free nerve endings in human lateral ankle ligaments. Foot Ankle Int. 2008;29(1):87-90.

29. Moore KL, Dalley AF. Clinically Oriented Anatomy. 4th ed. Baltimore, MD: Lippincott, Williams \& Wilkins; 1999.

30. Kendall F, McCreary E, Provance P, Rodgers M, Romani W. Muscles Testing and Function with Posture and Pain. 5th ed. Baltimore, MD: Lippincott, Williams \& Wilkins; 2005.

31. Backman LJ, Danielson P. Low range of ankle dorsiflexion predisposes for patellar tendinopathy in junior elite basketball players: a 1-year prospective study. Am. J. Sports Med. 2011;39(12):2626-2633.

32. Baumhauer J, Alosa D, Renstrom P, Trevino S, Beynnon B. A prospective study of ankle injury risk factors. Am. J. Sports Med. 1995;23(5):564-570.

33. Willems T, Witvrouw E, Delbaere K, Philippaerts R, De Bourdeaudhuij I, De Clercq D. Intrinsic risk factors for inversion ankle sprains in females - a prospective study. Scand J Med Sci Sports. 2005;15(5):336 - 345 .

34. Eils E, Schröter R, Schröder M, Gerss J, Rosenbaum D. Multistation Proprioceptive Exercise Program Prevents Ankle Injuries in Basketball. Med. Sci. Sports Exerc. 2010;42(11):20982105.

35. Verhagen E, A, Twisk J, Bouter L, Bahr R, van Mechelen W. The effect of a proprioceptive balance board training program for the prevention of ankle sprains: a prospective controlled trial. Am. J. Sports Med. 2004;32(6):1385-1393.

36. McGuine $T$, Keene J. The effect of a balance training program on the risk of ankle sprains in high school athletes. Am. J. Sports Med. 2006;34(7):1103-1111.

37. McHugh $M$, Tyler T, Mirabella M, Mullaney M, Nicholas $S$. The effectiveness of a balance training intervention in reducing the incidence of noncontact ankle sprains in high school football players. Am. J. Sports Med. 2007;35(8):1289-1294.

38. Tropp H, Askling C, Gillquist J. Prevention of ankle sprains. Am J Sports Med. 1985;13(4):259. 
39. Wedderkopp, N, Kaltoft M, Lundgaard B, Rosendahl M, Froberg K. Prevention of injuries in young female players in European team handball. A prospective intervention study. Scand J Med Sci Sports. 9(1):41-47.

40. Hertel J, Olmsted-Kramer LC. Deficits in time-to-boundary measures of postural control with chronic ankle instability. Gait Posture. 2007;25(1):33-39.

41. Pope M, Chinn L, Mullineaux D, McKeon PO, Drewes L, Hertel J. Spatial postural control alterations with chronic ankle instability. Gait Posture. 2011;34(2):154-158.

42. Nakagawa L, Hoffman M. Performance in static, dynamic, and clinical tests of postural control in individuals with recurrent ankle sprains. J. Sport Rehabil. 2004;13(3):255-268.

43. Sefton J, Hicks-Little C, Hubbard T, et al. Sensorimotor function as a predictor of chronic ankle instability. Clin. Biomech. 2009;24(5):451-458.

44. McKeon PO, Hertel J. Spatiotemporal postural control deficits are present in those with chronic ankle instability. BMC Musculoskelet. Disord. 2008;9:1-6.

45. Brown C, Bowser B, Orellana A. Dynamic Postural Stability in Females with Chronic Ankle Instability. Med. Sci. Sports Exerc. 2010;42(12):2258-2263.

46. Docherty C, McLeod T, Shultz S. Postural control deficits in participants with functional ankle instability as measured by the Balance Error Scoring System. Clin. J. Sport Med. 2006;16(3):203-208.

47. Olmsted L, Carcia C, Hertel J, Shultz S. Efficacy of the Star Excursion Balance Tests in detecting reach deficits in subjects with chronic ankle instability. J. Athl. Train. 2002;37(4):501-506.

48. Hertel J, Braham R, Hale S, Olmsted-Kramer L. Simplifying the Star Excursion Balance Test: analyses of subjects with and without chronic ankle instability. J. Orthop. Sports Phys. Ther. 2006;36(3):131-137.

49. Mangus B, Hoffman L, Hoffman M, Altenburger P. Basic principles of extremity joint mobilization using a Kaltenborn approach. J. Sport Rehabil. 2002;11(4):235-250.

50. Houglum P. Therapeutic Exercise for Musculoskeletal Injuries. 2nd ed. Champaign, IL: Human Kinetics; 2005.

51. Pertille A, Macedo A, Vieira, et al. Immediate Effects of Bilateral Grade III Mobilization of the Talocrural Joint on the Balance of Elderly Women. J. Manipulative Physiol. Ther. 2012;35(7):549-555.

52. Venturini C, Penedo M, Peixoto G, Chagas M, Ferreira M, De Resende M. Study of the force applied during anteroposterior articular mobilization of the talus and its effect on the dorsiflexion range of motion. J. Manipulative Physiol. Ther. 2007;30(8):593-597. 
53. De Souza M, Venturini C, Teixeira L, Chagas M, de Resen M. Force-displacement relationship during anteroposterior mobilization of the ankle joint. J. Manipulative Physiol. Ther. 2008;31(4):285-292.

54. Seiger C, Draper DO. Use of pulsed shortwave diathermy and joint mobilization to increase ankle range of motion in the presence of surgical implanted metal: A case series. J. Orthop. Sports Phys. Ther. 2006;36(9):669-677.

55. Prentice WE. Rehabilitation Techniques for Sports Medicine and Athletic Training. 4th ed. New York, NY: McGraw-Hill; 2004.

56. Martins DF, Mazzardo-Martins L, Gadotti VM, et al. Ankle joint mobilization reduces axonotmesis-induced neuropathic pain and glial activation in the spinal cord and enhances nerve regeneration in rats. Pain. 2011;152(11):2653-2661.

57. Martins DF, Mazzardo-Martins L, Cidral-Filho FJ, Stramosk J, Santos ARS. Ankle joint mobilization affects postoperative pain through peripheral and central adenosine A1 receptors. Phys. Ther. 2013;93(3):401-412.

58. Martins D, Bobinski F, Mazzardo-Martins L, et al. Ankle Joint Mobilization Decreases Hypersensitivity by Activation of Peripheral Opioid Receptors in a Mouse Model of Postoperative Pain. Pain Med. 2012;13(8):1049-1058.

59. Mulligan BR. Mobilisations with movement (MWM's. J. Man. Manip. Ther. 1993;1(4):154156.

60. Eils E, Rosenbaum D. A multi-station proprioceptive exercise program in patients with ankle instability. Med. Sci. Sports Exerc. 2001;33(12):1991-1998.

61. McKeon PO, Ingersoll CD, Kerrigan DC, Saliba E, Bennett BC, Hertel J. Balance training improves function and postural control in those with chronic ankle instability. Med. Sci. Sports Exerc. 2008;40(10):1810-1819.

62. Verhagen $E$, Bobbert $M$, Inklaar $M$, et al. The effect of a balance training programme on centre of pressure excursion in one-leg stance. Clin. Biomech. 2005;20(10):1094-1100.

63. Ben Moussa Zouita A, Majdoub O, Ferchichi H, Grandy K, Ben Salah FZ. The effect of 8-weeks proprioceptive exercise program in postural sway and isokinetic strength of ankle sprains of Tunisian athletes. Ann. Phys. Rehabil. Med. 2013;56:634 - 643.

64. Lee A, Lin W. Twelve-week biomechanical ankle platform system training on postural stability and ankle proprioception in subjects with unilateral functional ankle instability. Clin. Biomech. 2008;23(8):1065-1072.

65. Filipa A, Byrnes R, Paterno M, Myer G, Hewett T. Neuromuscular training improves performance on the star excursion balance test in young female athletes. J. Orthop. Sports Phys. Ther. 2010;40(9):551-558. 
66. Romero-Franco N, Martínez-Amat A, Hita-Contreras F, Martínez-López EJ. Short-term Effects of a Proprioceptive Training Session with Unstable Platforms on the Monopodal Stabilometry of Athletes. J. Phys. Ther. Sci. 2014;26(1):45-51.

67. Romero-Franco N, Martínez-López EJ, Lomas-Vega R, Hita-Contreras F, Osuna-Perez MC, Martínez-Amat A. Short-term effects of proprioceptive training with unstable platform on athletes' stabilometry. J Strength Cond Res. 2013;27(8):2189-2197.

68. Hardy L, Huxel K, Brucker J, Nesser T. Prophylactic ankle braces and star excursion balance measures in healthy volunteers. J. Athl. Train. 2008;43(4):347-351.

69. Sawkins K, Refshauge K, Kilbreath S, Raymond J. The Placebo Effect of Ankle Taping in Ankle Instability. Med. Sci. Sports Exerc. 2007;39(5):781-787.

70. Delahunt E, McGrath A, Doran N, Coughlan GF. Effect of Taping on Actual and Perceived Dynamic Postural Stability in Persons With Chronic Ankle Instability. Arch. Phys. Med. Rehabil. 2010;91(9):1383-1389.

71. Laudner KG, Moline M, McLoda TA, McCaw S. Talocrural joint mobilization's lack of effect on postural control in healthy subjects. J. Sport Rehabil. 2011;epub only. 